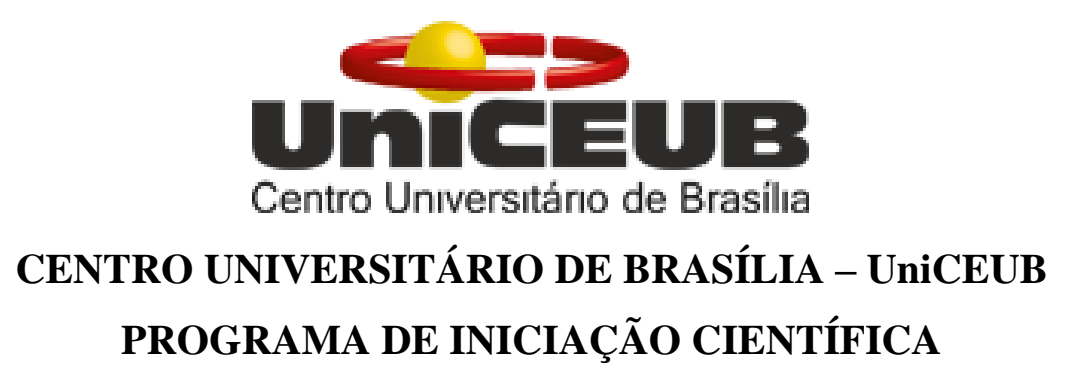

CONVERSÃO DA ENERGIA DAS ONDAS ELETROMAGNÉTICAS ARTIFICIAIS DOS MEIOS URBANOS EM ENERGIA ELÉTRICA

\author{
DIOGO FERNANDES GOMES \\ FRANCISCO JAVIER DE OBALDIA DIAZ
}

BRASÍLIA - DF

2019 
DIOGO FERNANDES GOMES

CONVERSÃO DA ENERGIA DAS ONDAS ELETROMAGNÉTICAS ARTIFICIAIS DOS MEIOS URBANOS EM ENERGIA ELÉTRICA

Relatório final de pesquisa de Iniciação Científica apresentado à Assessoria de PósGraduação e Pesquisa.

Orientação: Prof. MsC. Francisco Javier de Obaldía Díaz

BRASÍLIA - DF

2019 
Gomes, Diogo Fernandes.

CONVERSÃO DA ENERGIA DAS ONDAS ELETROMAGNÉTICAS ARTIFICIAIS DOS MEIOS URBANOS EM ENERGIA ELÉTRICA/ Diogo Fernandes Gomes; orientador Francisco Javier de Obaldía Díaz, 2019. 57 p.

Relatório final de pesquisa de Iniciação Científica (graduação) - Centro Universitário de Brasília, FATECS - Faculdade De Tecnologia E Ciências Sociais Aplicadas, Graduação em engenharia elétrica, Brasília DF, 2019. 


\section{AGRADECIMENTO}

Agradeço primeiramente à Deus por ter me dado força e sabedoria para concluir mais essa valiosa etapa da minha vida.

Agradeço aos meus pais, Everaldo e Fatima que apesar de todas as dificuldades me apoiaram durante todo o processo de elaboração desta presente pesquisa.

Ao meu orientador Francisco Javier de Obaldia Diaz por todo apoio, por acreditar em mim valorizando minha pesquisa, pela paciência ao longo da elaboração deste projeto e pelo compromisso firmado e cumprido para melhor realização deste.

Também gostaria de deixar um agradecimento especial as professoras Claudia Ochoa e Erondina Azevedo por auxiliar com valorosas referências bibliográficas.

Agradeço a minha instituição de ensino UniCeub por possibilitar a excussão deste trabalho e em especial a coordenação de Assessoria de pesquisa e extensão e a sua maravilhosa equipe sempre prestativos.

Agradeço a Escola de Comunicações do Exercito por ter aberto as portas para nos auxiliar e disponibilizar suas oficinas para implementação desta pesquisa, e em particular ao sargento Marcelo Rebolças e ao tenente André Ricardo por total dedicação...

Gostaria de deixar meu profundo agradecimento a Analha Brito por todo empenho e colaboração no decorrer da produção deste trabalho.

E agradecer a todas as pessoas que direta ou indiretamente contribuíram para a realização desta pesquisa. 
RESUMO

\title{
CONVERSÃO DA ENERGIA DAS ONDAS ELETROMAGNÉTICAS ARTIFICIAIS DOS MEIOS URBANOS EM ENERGIA ELÉTRICA
}

\author{
Diogo Fernandes Gomes - UniCEUB, PIC Institucional, aluno bolsista \\ Diogo.fernandes@sempreceub.com
}

Francisco Javier de Obaldia Diaz - UniCEUB, professor orientador

francisco.javier@ceub.edu.br

$\mathrm{Na}$ atualidade, métodos de fontes alternativas de energias são alvos frequentes de estudos, com o intuito de mitigar as ações prejudiciais das mais diversas fontes de energias fósseis. Inúmeras tecnologias fazem usos de micro-ondas para estabelecer comunicação entre si, assim passa a existir diversas fontes de ondas eletromagnéticas sendo irradiada cotidianamente no espaço livre, sem utilização eficaz, abrindo espaço para o desenvolvimento de técnicas de colheitas de energia do meio ambiente do inglês energy harvesting. Na presente pesquisa foi realizado um projeto no qual consiste no reaproveitamento de energia eletromagnética dos meios urbanos denominada rectenna, sendo este formado basicamente por uma antena com um circuito retificador. A rectenna tem como objetivo interagir com fenômenos eletromagnéticos para converte-los em eletricidade. Por fim, foi simulado um sistema de arranjo de dezesseis elementos irradiantes de microfitas retangular com frequência de ressonância de 2,45 Ghz no software ADS $®$ e verificado os seus parâmetros fundamentais, tais como: ganho, diretividade e eficiência.

Palavras-Chave: Rectenna. Micro-ondas. Energy harvesting. 


\begin{abstract}
Today, alternative methods of energy sources are frequent targets of studies to mitigate the harmful actions of the most diverse fossil energy sources. Numerous technologies make use of microwaves to communicate with each other, so there are several sources of electromagnetic waves that radiate daily in free space, without effective use, leaving room for the development of environmental energy collection techniques. Collection of energy. In the present investigation, a project was carried out in which it consists of the reuse of electromagnetic energy from urban areas called rectenna, which is basically formed by an antenna with a rectifier circuit. Rectenna aims to interact with electromagnetic phenomena to convert them into electricity. Finally, in the ADS ${ }^{\circ}$ software, an arrangement of sixteen radiating micron matrix elements with resonant frequency of $2.45 \mathrm{Ghz}$ was simulated and its fundamental parameters were verified, such as: gain, directivity and efficiency
\end{abstract}

Palavras-chave: Rectenna. Microwave. Energy harvesting. 


\section{Sumário}

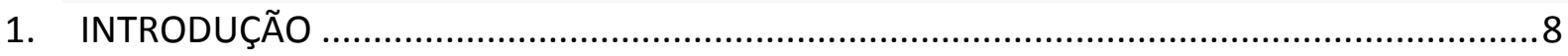

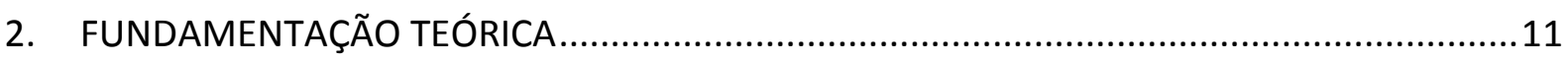

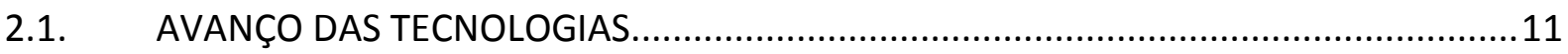

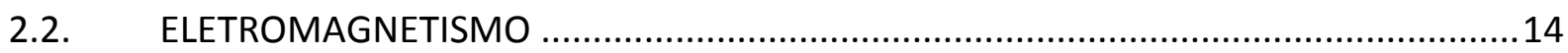

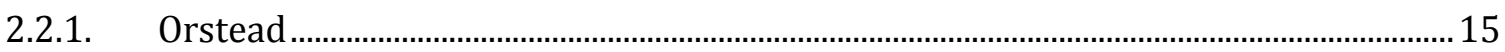

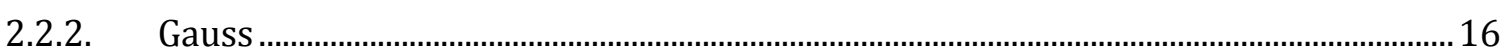

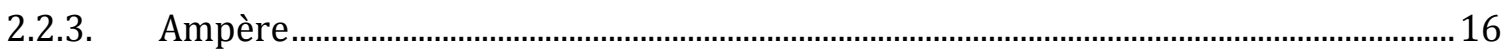

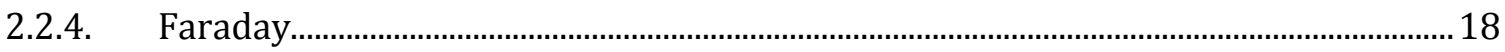

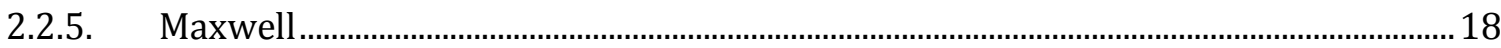

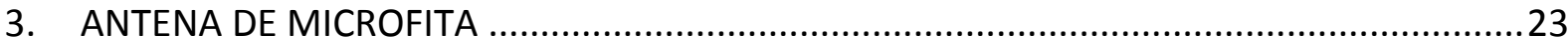

3.1. MODELOS DE PATCH E TÉCNICAS DE EXCITAÇÃO …................................................24

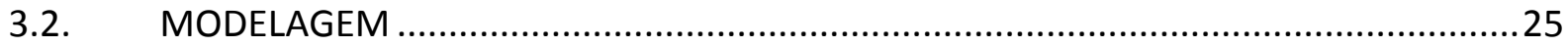

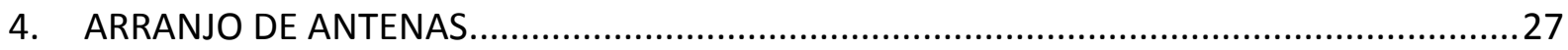

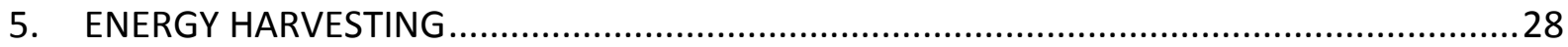

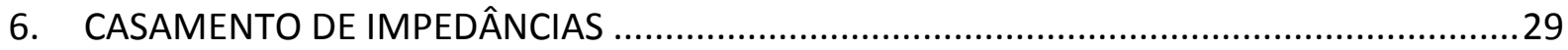

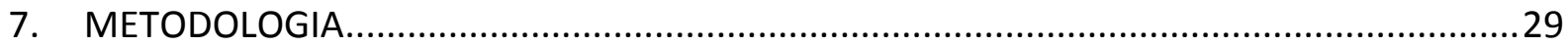

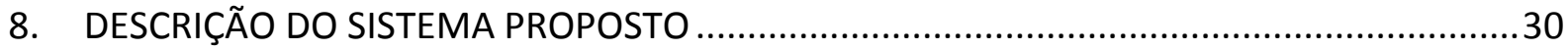

8.1. ESTAÇÕES DO SMP (CELULAR 2G, 3G E 4G) .....................................................

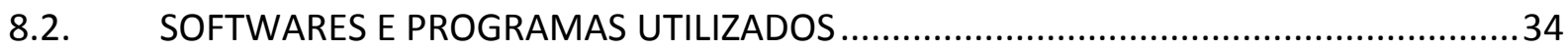

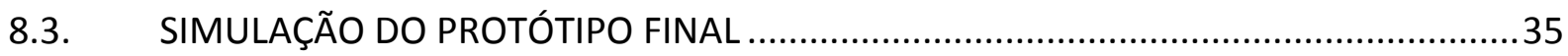

8.3.1. Desenvolvimento do primeiro elemento ………………………………......................... 36

8.3.2. Arranjo de dois elementos ................................................................................................... 44

8.3.3. Arranjo de quatro elementos .......................................................................................... 45

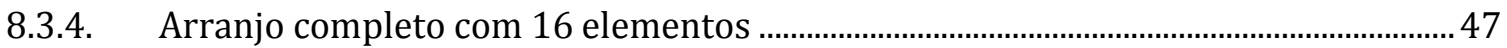

9. CIRCUITO RETIFICADOR E DOBRADOR DE TENSÃO ….................................................

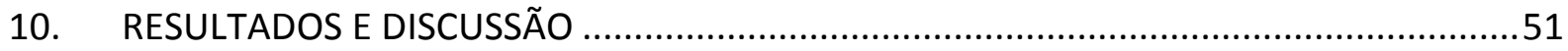

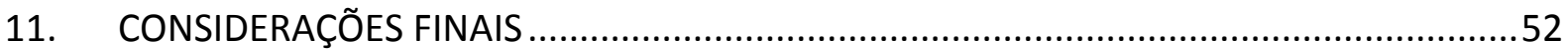

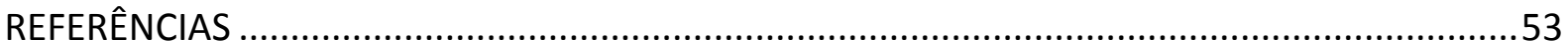




\section{INTRODUÇÃO}

Energia é um conceito abstrato que está relacionado a realização de trabalho. De maneira didática podemos dizer que energia é aquilo que devemos pagar para fazermos as coisas. Desta maneira, qualquer sistema que deseja imprimir uma força, deve ter disponível uma fonte de energia para custear o trabalho ${ }^{[1]}$. A energia pode ter diversas formas, entre elas podemos destacar a energia cinética, calorifica, eletromagnética, elétrica e química, onde todas estas são intercambiáveis entre si, diferindo-se na forma em que são dispostas na natureza e nas suas peculiaridades em provocar fenômenos característicos dentro dos sistemas físicos. É válido ressaltar propriedades inerentes a energia onde dentro de suas transformações físicas há total conservação da mesma.[1]

A eletricidade é uma das melhores formas de se obter energia, sendo bastante versátil, podendo ser produzida, transmitida e armazenada de forma relativamente simples e com baixo custo benefício, sendo esta, propulsora de muitas tecnologias, sobretudo na área aeroespacial, de telecomunicações, hospitalar e bélica. A partir dos avanços científicos e da inserção de novas tecnologias, o cotidiano das pessoas vem sofrendo alterações. ${ }^{[2]}$ Este progresso da inovação tecnológica, atua de forma direta e indireta alterando a forma anterior de como fazemos as coisas, desta maneira, passa a existir uma transformação na estrutura, nas práticas e também no modo de como efetuamos as atividades cotidianas, tais modificações podem ser consideradas destrutivas, já que com o desenvolvimento tecnológico a forma de realizar essas atividades tem se distanciado daquela de outrora, tornando-a obsoleta. ${ }^{[3]}$

Com a evolução dos meios tecnológicos, as relações pessoais foram diretamente modificadas. Passamos brevemente da escrita de cartas em papeis entregues pelo correio, para e-mails enviados instantaneamente para qualquer parte do mundo, sem falar no uso de aplicativos em nossos smartphones, tablet e desktop, que gerenciam quase tudo a nossa volta (internet das coisas).[4]

A comunicação global por meio de aparelhos eletrônicos reduziu as distâncias, entretanto isso só é possível através dos enlaces de transmissão imperceptível da cobertura de rádio difusão, dispensando cada vez mais os meios físicos de conexão entre transmissor e receptor, deste modo, grande parte do envio de informações é feita através de ondas eletromagnéticas.[5]

O eletromagnetismo é a base para a telecomunicação mundial. Sendo este o meio utilizado para levar as informações aos seus destinatários, a tendência é que os pacotes de dados sejam maiores e necessitem de maior largura de banda para o seu envio, abrindo portas para o desenvolvimento de algoritmos de otimização de envio de dados ou de maneiras 
seguras de manipular sinais com maior nível de frequência, aumentando assim sua largura de banda, entretanto reduzindo seu alcance funcional. Desta forma, para transmissão em longas distâncias com sinais de alta frequência, faz-se necessário um número maior de antenas e satélites disponíveis para repetir o sinal emitido. ${ }^{[6]}$ Grande parte das regiões do mundo possuem vários satélites e torres formando uma cobertura global de transmissão através do uso de antenas, promovendo uma interconexão mundial de comunicação.

O número de ondas sendo irradiadas diariamente vem crescendo cada vez mais, com uma infinidade de frequência e intensidade de sinal. Somos envolvidos todos os dias por radiação eletromagnética - oriunda de sinais de rádio e televisão, tal como de uma sucessão de tecnologias, englobando fontes naturais, como a luz solar.[5]

Podemos observar a grande disponibilidade de sinais eletromagnéticos em nossos smartphones, como as inúmeras redes WI-FI, operadoras de telefonia, sinais de canais de televisão e rádio, como a figura abaixo exemplifica.

Figura 1.1: Exemplos de dispositivos que transmitem e recebem ondas.

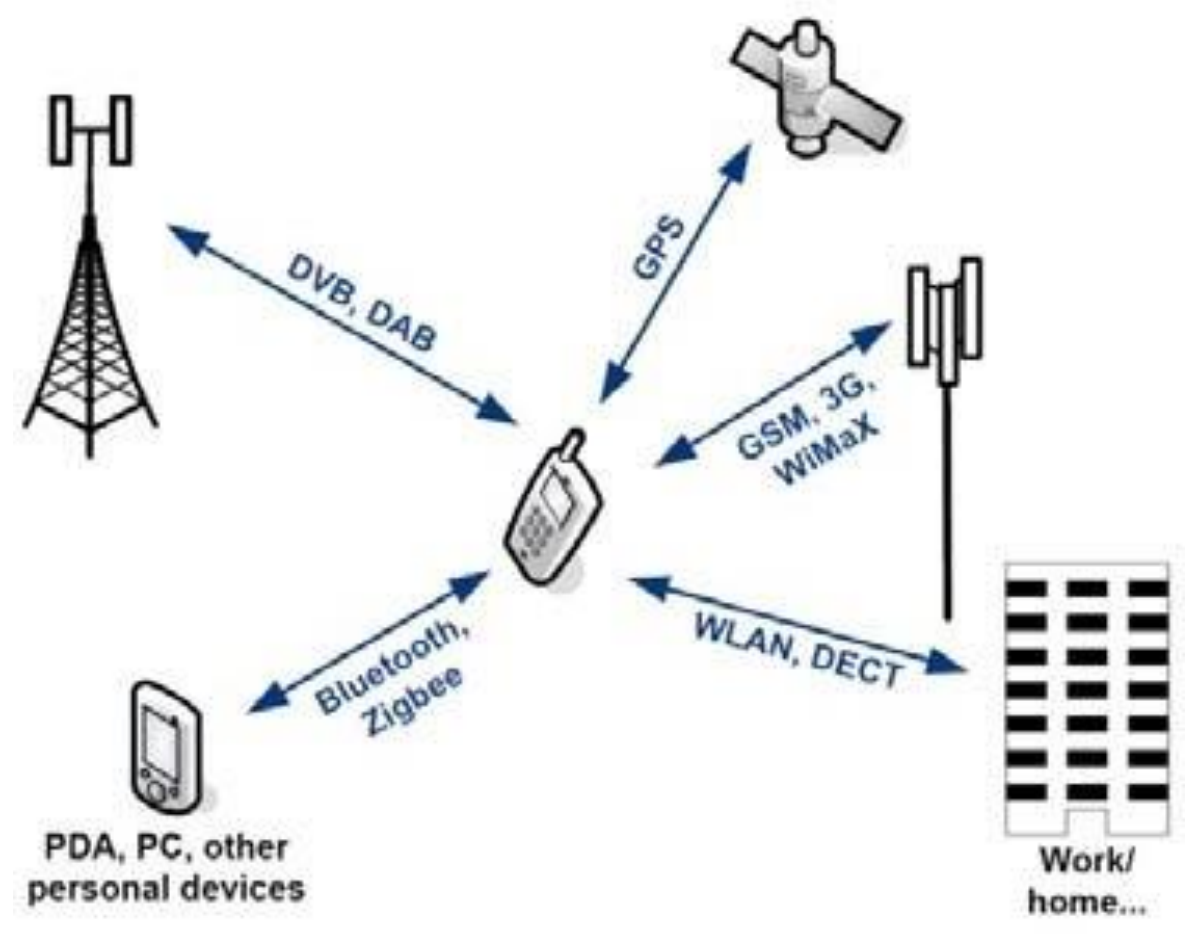

Fonte: Center for Software Defined Radio.[7] 
Esta quantidade de sinais ondulatórios invisíveis inseridos em nosso meio precisa ser gerenciada e regulamentada para que não ofereça nenhum tipo de dano a nossa saúde. Órgãos como a Organização Mundial da Saúde - OMS e a Comissão Internacional de Proteção Contra Radiação Não Ionizante - ICNIRP vem se preocupando com os sinais não-ionizantes (RNI), ou seja, ondas eletromagnéticas que não causem mutações ao DNA, com base nisso formulam normas que sendo seguidas asseguram que tais avanços tecnológicos como o advento do 5G, que já está sendo testado em alguns países, não sejam prejudiciais a saúde. Entretanto, mesmo que as ondas eletromagnéticas das telecomunicações permaneçam nãoionizantes, a pluralidade dos diversos sinais artificiais em nosso meio é assustadora, e assim, podemos falar no termo de poluição eletromagnética e suas consequências. ${ }^{[8]}$

A poluição eletromagnética, assim como os demais tipos de poluição, pode ser nociva à saúde, se expostos a radiação por um logo período. Efeitos térmicos e atérmicos estão sendo analisados por diversos estudiosos para garantir a saúde pública e os direitos sociais de se ter um meio ambiente equilibrado previsto nas leis ambientais. ${ }^{[9][10]}$ Entretanto, a vasta gama de ondas eletromagnéticas abre portas/espaço para uma técnica de obtenção de energia contida no ambiente, denominado energy harvesting.

Energy harvesting, em uma tradução literal, quer dizer, "colheita de energia", e possui como finalidade a obtenção de energia das formas mais distintas possíveis do meio, como por exemplo: vibração de estruturas, próprio movimento ou calor humano e agitação das marés. Inicialmente são esperadas baixas potências destes tipos de fontes, o que nos leva a analisar se é rentável o esforço para obter energia de diversas origens. Entretanto, quando observado que tais energias estão disponíveis e constantemente sendo geradas, o uso da superposição de diversas fontes de energia torna-se mais atrativa podendo ser suficiente para melhorar o rendimento ou até mesmo suprir completamente circuitos de baixa potência, desta maneira diversos dispositivos estão sendo desenvolvidos com a finalidade de coletar energias do meio ambiente.[11][12]

Com base nisto, esta pesquisa apresenta o estudo e desenvolvimento de um protótipo para conversão de ondas eletromagnéticas não-ionizantes em eletricidade. Tal estudo adotou a faixa de micro-ondas em meios urbanos com a finalidade de coletar energia deste tipo de fonte para suprimento de uma bateria de 12 voltes. 


\section{FUNDAMENTAÇÃO TEÓRICA}

Nos últimos anos com o encarecimento da extração das reservas finitas de petróleo, a metamorfose da matriz energética para a utilização das fontes de energias renováveis tem se tornado um grande desafio mundial da nossa era. Desta forma, a busca por aprimoramento e desenvolvimento tecnológico para obter-se formas mais eficientes e inteligentes de geração e transmissão de energia para a realização do trabalho, ainda, de maneira mais barata e otimizada da produção da mesma..

O reaproveitamento do calor dos motores e turbinas à combustão, para auxílio de produção de energia em máquinas térmicas secundárias, a utilização do bagaço da cana de açúcar para produção do biodiesel, a gordura dos animais e os restos alimentares para a biomassa, são apenas alguns exemplos da otimização do rendimento na aquisição de energia. Outra forma de melhorar a eficiência e rendimento da produção de energia é o reaproveitamento dos resíduos residenciais, industriais e hospitalares. A reciclagem e os reatores de leitos fluidizados são práticas que precisam ser incentivadas, tendo em vista a degradação dos recursos finitos do planeta e o aumento da poluição. Existem diversos tipos de poluição, e é fundamental ressaltar a importância em se falar de poluição eletromagnética.

Com o aumento dos serviços de telecomunicações, o índice de poluição eletromagnética incidente em nosso meio tem se intensificado e tem tomado a atenção das comunidades científicas.

Assim, este trabalho abrange o estudo e o desenvolvimento de meios para fazer uso das ondas eletromagnéticas que incidem os meios urbanos transformando-a em eletricidade, onde tal processo pode ser visto como uma forma de "reciclagem" transformando um tipo de energia diretamente em eletricidade.

\subsection{AVANÇO DAS TECNOLOGIAS}

Desde as primeiras observações de fenômenos magnéticos na Grécia antiga, e posteriormente as pesquisas que contribuíram à formalização do eletromagnetismo, o homem tem evoluído e se tornado cada vez mais dependente dos recursos tecnológicos, como a produção de energia elétrica potencial, cujo uso é indispensável nos dias atuais, tornando-se o alicerce para a segurança e conforto, o qual abrange a sustentabilidade do modo de vida das novas eras. Dessa forma com os avanços tecnológicos, e devido às questões energéticas em 
pauta é comumente aceitável, que com as reservas finitas do petróleo, a energia elétrica seja a energia do futuro.[13]

A ideia de transporte de energia sem acoplamento elétrico/galvânico genericamente designado por Wireless Power Transfer (WPT), já era foco em pesquisas de grandes estudiosos como, Nikola Tesla, que em 19xx, a partir de seu projeto Wardenclyffer Tower localizado em Shoreham, Long Island proporcionou uma grande inspiração para projetos revolucionários.[14]

Figura 2.1: A imagem abaixo retrata o projeto de Tesla, que tinha o objetivo de transmitir energia sem o uso de fios.

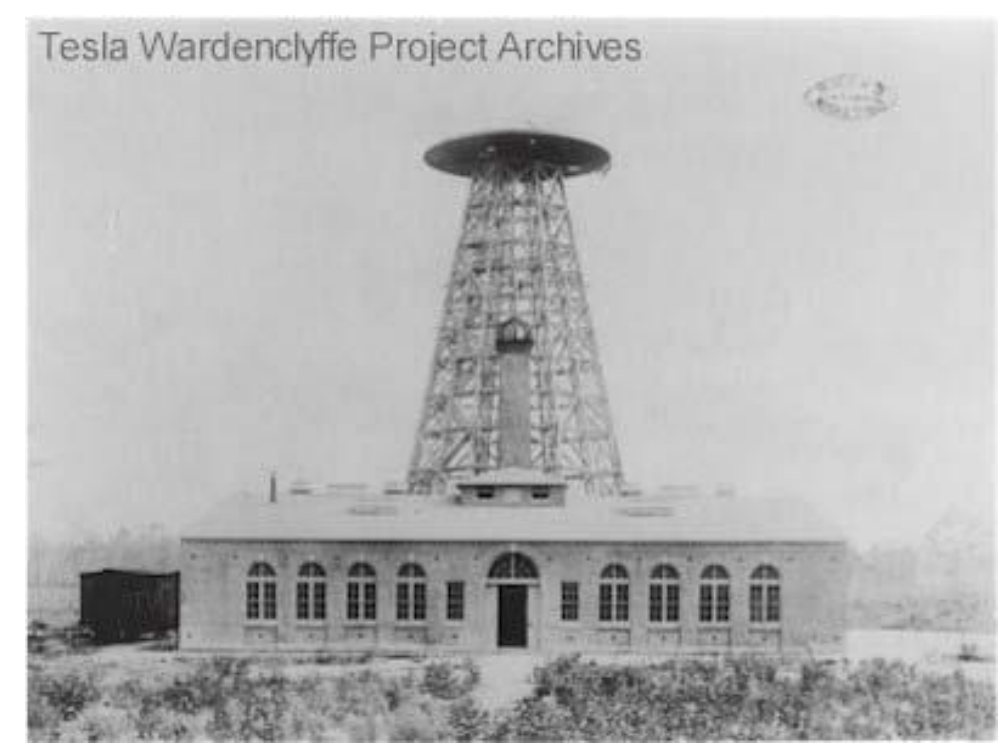

Fonte: Arquivo de fotos do TWP Nikola Tesla.[15]

Algumas outras formas de transmissão de energia sem fio foram desenvolvidas, como a de Peter Glaser, 1961, que com sua publicação, sugeriu que a conversão de energia solar em energia elétrica, feita em satélites, na órbita terrestre, fosse transmitida em forma de microondas e assim poderia enviá-las para receptores em solo. Atualmente, tal sistema é conhecido como Space-Based Solar Power (SBSP) [16].

Em 1988, em uma publicação na revista Popular Science sobre WPT [17], o pioneiro da área de transporte de energia por micro-ondas, William C. Brown, foi citado tendo em vista a sua contribuição por meio da produção do documento intitulado "Microwave energy for power transmission”. A partir desse estudo, foi comprovado que era possível utilizar a conversão de ondas eletromagnéticas para suprimento efetivo de uma carga. 
William C. Brown foi pesquisador em um programa da National Aeronautics and Space Administration - NASA, e melhorou consideravelmente um projeto já existente de uma antena receptora de micro-ondas na faixa de 2.45 a 20 [GHz]. Essa antena ficou conhecida como rectenna, pois tal dispositivo fazia o trabalho de receber o sinal AC e o transformava para DC, com alto nível de rendimento [18].

Figura 2.2: mostra o circuito da rectenna de Wiliam, onde os blocos F são os filtros passivos para a frequência de $2.45 \mathrm{GHz}$, justamente com vários dipolos de alumínio.

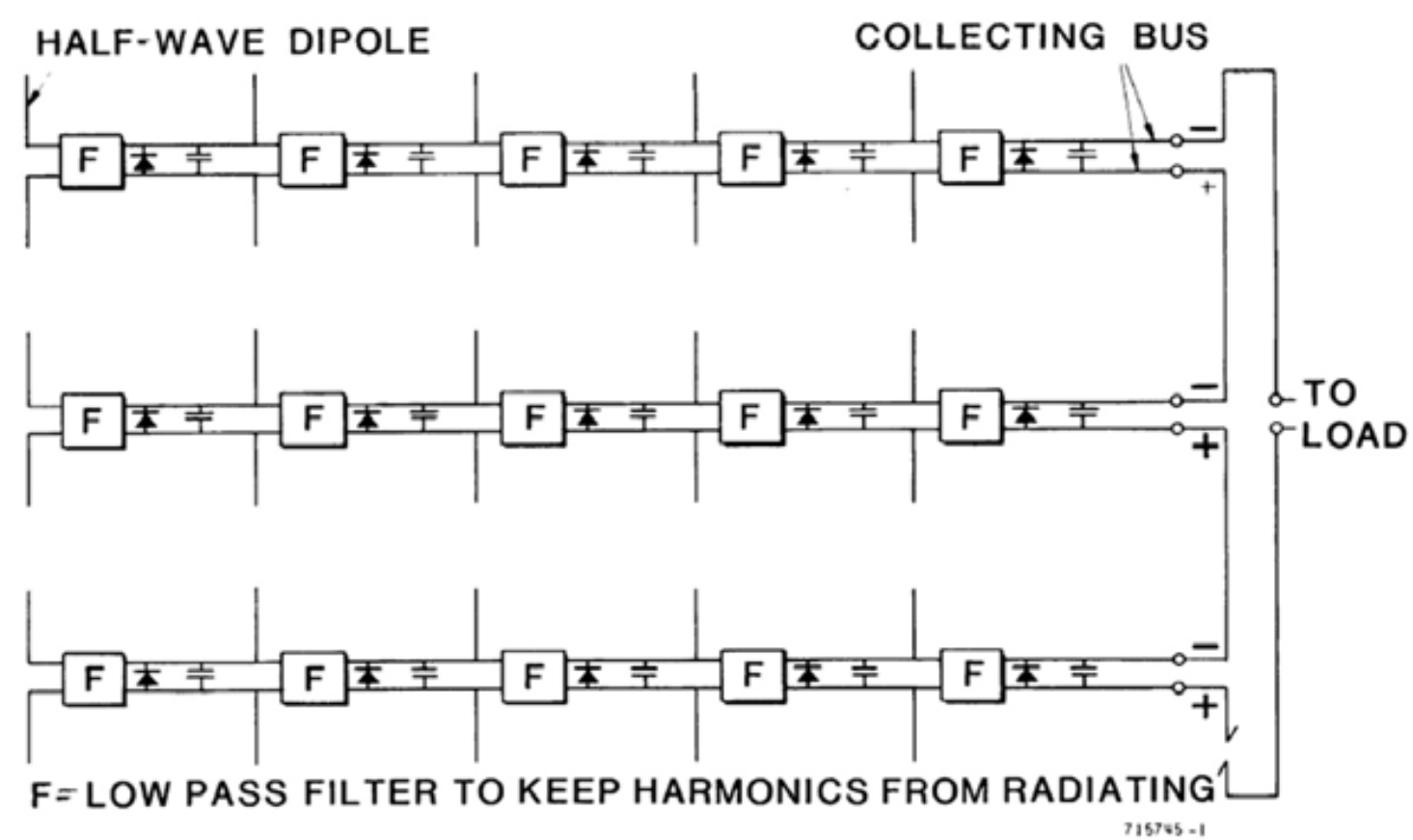

Fonte: Rectenna Technology Program: Ultralight 2.45 Ghz rectenna and 20 GHz rectenna [18]

William C. Brown fez parcerias com outras empresas na área de WPT, desenvolvendo o diodo schottky com a empresa $\mathrm{HP} 囚$, também foi responsável pelo casamento de impedância que possibilitou alguns testes impressionantes onde alimentava um pequeno helicóptero que voava a uma altura de 60ft (aproximadamente 18 metros), isso por várias horas. Esse helicóptero tinha seu suprimento energético proveniente de um transmissor de micro-ondas construído especialmente para o suprimento do helicóptero, que em sua estrutura tinha uma rectenna [19]. 
Figura 2.3: A imagem (à esquerda) retrata a foto da estrutura completa da rectenna utilizada por W. C Brown acoplando a um motor com hélice formando o seu helicóptero; e a figura 2.2 (à direita), mostra Wiliam assistindo o voo de seu helicóptero a uma altitude de aproximadamente 18 metros sendo estabilizado por alguns cabos de aço.
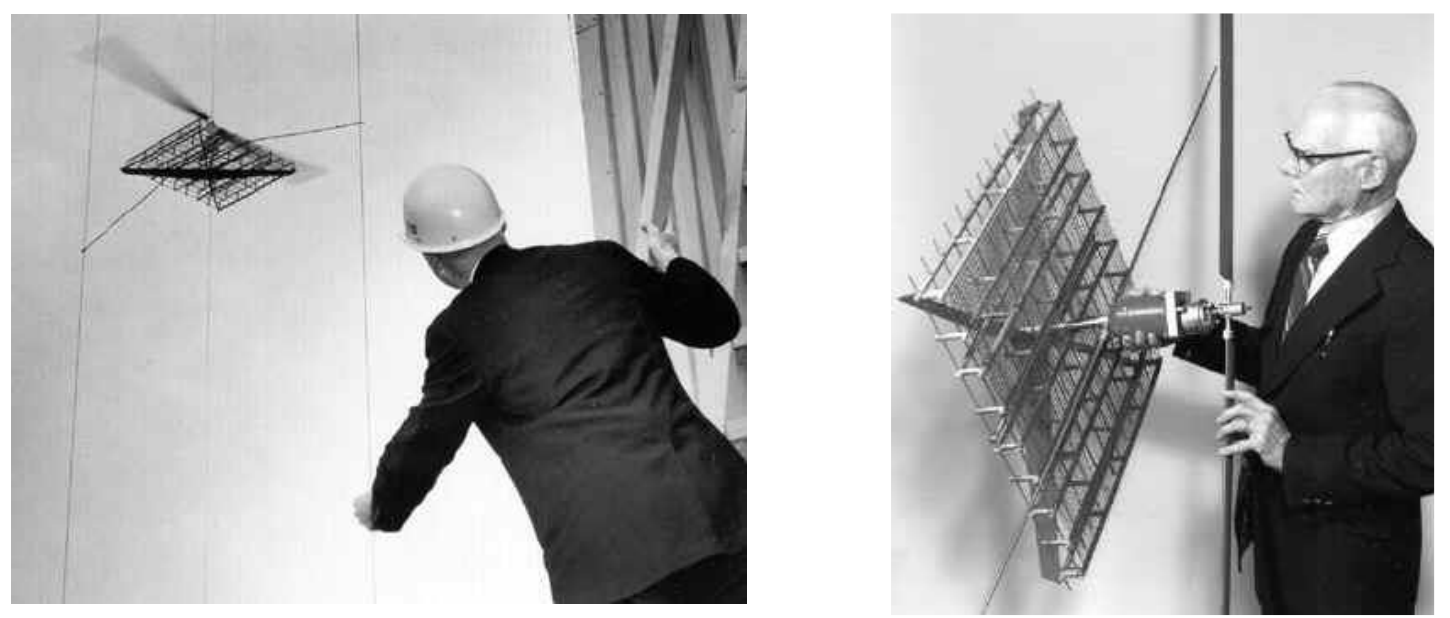

Fonte: IEEE Microwave Theory and Techniques Society [19].

O trabalho de William C. Brown e Peter Glaser tinham em comum um transmissor especificamente criado para suprir suas demandas de energia. O estudo realizado no presente projeto de pesquisa, teve como objeto de análise as ondas já existentes dos meios comuns urbanos, visando seu aproveitamento energético, não se importando com suas finalidades de transporte de dados, focando essencialmente na recepção do sinal e retificação e armazenamento do mesmo. Atualmente, diversos estudos estão sendo realizados com a finalidade de usar como suprimento energético ondas eletromagnéticas, como é o caso do presente projeto de pesquisa.

\subsection{ELETROMAGNETISMO}

Para entender-se melhor a função e definição de uma antena, precisa-se compreender alguns aspectos das ondas eletromagnéticas. As equações de James Clerk Maxwell, brilhantemente correlaciona os estudos de várias mentes brilhantes como Hans C. Orstead, Carl F. Gauss, Andre M. Ampère, Michael Faraday, tal como o seu próprio incremento com sua teoria de "corrente de deslocamento" entre outras. Desta forma Maxwell formalizou o que posteriormente veio a chamar-se equações de Maxwell, demonstrando teoricamente, que perturbações magnéticas e elétricas podem atuar como a face da mesma moeda propagando-se 
pelo espaço livre. Deste modo surgiu o conceito de uma onda que dispensa meios de propagação denominada de onda eletromagnética [20].

A seguir uma breve introdução acerca das contribuições teóricas, feitas por cientistas, para as formulações das equações que regem o eletromagnetismo.

\subsubsection{Orstead}

Hans Christian Oersted, foi um professor de física e química no século XVIII, na Universidade de Copenhague, onde uma das suas maiores contribuições para a ciência veio de uma observação enquanto fazia alguns experimentos. Orstead verificou que ao passar uma corrente elétrica por um condutor, a agulha de uma bússola que estava perto do condutor se movimentava assumindo uma nova posição, onde concluiu se que, havia uma produção de um campo magnético oriundo da movimentação da corrente elétrica no condutor. E assim foi estabelecido de certa forma uma correlação inerente dos fenômenos elétricos e magnéticos, tendo em vista que para sua época tais fenômenos ainda eram tratados com total independência um do outro, mesmo que a comunidade científica procurasse uma relação intima entre os fenômenos [21][22].

Figura 2.4: A imagem abaixo ilustra a agulha de uma bússola sofrendo influência do campo magnético provocado pela existência de corrente elétrica no condutor

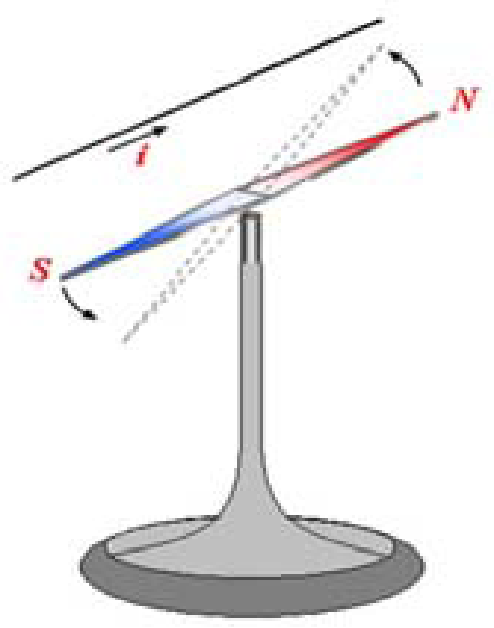

Fonte: Brasil Escola [22]. 


\subsubsection{Gauss}

Johann Carl Friedrich Gauss contribuiu significativamente para o estudo nas áreas de matemática, física e astronomia, assim como diversas outras áreas. Contudo, para o eletromagnetismo foram estabelecidas duas leis, que ficaram conhecidas na física como lei de Gauss para a eletricidade e lei de Gauss para o magnetismo. Dessa forma para a eletricidade é estabelecida uma superfície fechada (abstrata) onde o fluxo resultante elétrico que atravessa tal superfície gaussiana é igual à carga elétrica total em seu interior dividida por um fator constante de permissividade elétrica no vácuo [23] [24] [25].

As equações 1 e 2 descrevem a lei de Gauss matematicamente, onde $\boldsymbol{\epsilon}_{\mathbf{0}}=$ constante de permissividade elétrica no vácuo. $\boldsymbol{\phi}=$ fluxo elétrico resultante, e $\boldsymbol{q}=$ carga elétrica envolvida.

$$
\begin{aligned}
& \boldsymbol{\epsilon}_{\mathbf{0}} \oint \boldsymbol{E} \boldsymbol{d A}=\boldsymbol{q}_{\text {env }} \\
& \boldsymbol{\phi}=\frac{\boldsymbol{q}}{\epsilon_{0}}
\end{aligned}
$$

Com relação ao magnetismo, a lei de Gauss informa que em uma região onde existe um campo magnético o fluxo que atravessa a superfície fechada vai ser sempre nulo, tendo em vista que não existem monopolos magnéticos, portanto a integral fechada aplicando essa lei é zero [25][26].

\subsubsection{Ampère}

André-Marie Ampère, um grande estudioso e famoso por suas contribuições nas pesquisas sobre fenômenos eletrodinâmicos, e por esse motivo foi homenageado tendo seu nome a unidade de corrente elétrica, o Ampère, designado com a letra A maiúscula. Contudo uma das suas maiores contribuições foi o desenvolvimento para o cálculo de campos elétricos e magnéticos envolvidos por uma superfície fechada entorno de condutores percorridos por uma corrente elétrica, denominada de amperiana, descrita matematicamente a seguir.

Entretanto, sendo que para o caso de não haver algum tipo de simetria na superfície amperiana, será necessário o uso de dispositivos computacionais para realizar os devidos cálculos. Embora a lei tenha recebido o nome de Ampère, devido a influencias do físico 
Cleark Maxwell, é possível demonstra-la através da lei de Biot - Savart, descrita pelos estudiosos Jean Baptiste Biot e Félix Savart. Contudo, para a formalização dos estudos de ondas eletromagnéticas foi usado uma nova lei estruturada na lei de Ampère, onde foi anexado um novo complemento por Maxwell, o qual teve a brilhante ideia baseada em uma simetria dos princípios físicos, onde veio a propor basicamente o sentido inverso da lei de Faraday que, se a interação entre a variação de um fluxo elétrico $\Phi_{\mathrm{E}}$ produziria um campo magnético $\overrightarrow{\mathrm{B}}$, dando origem a lei de Maxwell da indução. A junção da lei de Ampère e o complemento da lei de Maxwell da indução, formalizou uma nova lei homenageando os dois pesquisadores - a lei de Ampère-Maxwell [27][28].

A equação a seguir descreve matematicamente a Lei de Ampère.

$$
\oint \vec{B} \cdot d \vec{s}=\mu_{0} i_{e n v}
$$

Onde $B$ é o campo magnético, s é o seguimento infinitesimal da superfície e i a corrente envolvida pela superfície

A equação a seguir descreve matematicamente a lei formulada por Jean Baptiste Biot e Félix Savart para melhor explicar os fenômenos gerados por uma corrente elétrica em um material condutor e as correlações com o campo magnético.

$$
|B|=K_{m} \frac{|q| V \cdot \sin (\alpha)}{r^{2}}
$$

A equação abaixo descreve a formulação da lei de Maxwell da indução.

$$
\oint \vec{B} \cdot d \vec{S}=\mu_{0} \epsilon_{0} \frac{d \Phi_{E}}{d t}
$$

E a equação a seguir descreve matematicamente a junção da Lei de Ampère e a Lei de Maxwell.

$$
\oint \vec{B} \cdot d \vec{S}=\mu_{0} \epsilon_{0} \frac{d \Phi_{E}}{d t}+\mu_{0} i_{e n v}
$$




\subsubsection{Faraday}

Michael Faraday um físico e químico que contribuiu com várias pesquisas no campo da eletroquímica, sendo o mesmo o criador de algumas definições como os termos cátion, ânion, eletrodo, eletrolítico, como vários outros termos importantes para a ciência como é conhecida hoje. Faraday com seus estudos analisou que uma força eletromotriz e uma corrente elétrica são induzidas em uma espira sendo permeada por linhas de campo magnético, onde o número de linhas de campo que permeia a espira não tem muito valor e sim a taxa de variação dos números dessas linhas, tais colocações formulam a lei de indução de Faraday. Contudo posteriormente esse efeito será comprovado que acontece em qualquer material condutor [27][29].

Essa equação descrita abaixa refere-se à lei de indução de Faraday.

$$
\oint \vec{E} \cdot d \vec{S}=-\frac{d \Phi_{E}}{d t}
$$

Onde E é o campo elétrico.

\subsubsection{Maxwell}

James Clerk Maxwell fazendo uso de um vasto acumulo de informações acerca dos fenômenos elétricos e magnéticos, foi capaz de abstrair e consolidar uma série de estudos de grandes pesquisadores como os citados acima, onde foi desenvolvido um conjunto de equações que possibilitou a unificação dos eventos elétricos, magnéticos e assim como as perturbações ópticas, em um esquema bem organizado e harmonioso; Maxwell condensou tudo e podendo-se resumidamente expor as formas diferenciais de suas famosas equações [30][31].

A Lei de Faraday relaciona o campo elétrico induzido à criação do fluxo magnético.

$$
\nabla \times \vec{e}=\vec{m}-\frac{\partial \vec{b}}{\partial t}
$$

A Lei de Ampère-Maxwell relaciona o campo magnético induzido à variação do fluxo elétrico e à corrente. 


$$
\nabla \times \vec{h}=\vec{\jmath}+\frac{\partial \vec{d}}{\partial t}
$$

A Lei de Gauss elétrica relaciona o fluxo elétrico às cargas elétricas envolvidas.

$$
\nabla \mathbf{x} \overrightarrow{\boldsymbol{d}}=\boldsymbol{\rho}
$$

Lei de Gauss magnética relaciona o fluxo magnético às cargas magnéticas envolvidas.

$$
\nabla \times \vec{d}=0
$$

Maxwell não só descreveu como era a relação entre os campos elétricos e magnéticos durante a propagação, mas também aspectos da sua velocidade, onde tinha total similaridade com a própria luz. Entretanto, as comprovações de tais teorias só se deram com o experimento de Heinrich Hertz que na década de 1880, comprovou experimentalmente a propagação das ondas eletromagnéticas fazendo a primeira transmissão e recepção desse fenômeno que mais tarde ficou conhecido como ondas de rádio. Hertz contribui com muitos outros estudos ajudando a caracterizar as ondas eletromagnéticas [32] [33].

Figura 2.5: A imagem abaixo ilustra o experimento de Hertz que constitui um circuito oscilador feito basicamente com um SWITCH (Interruptor), duas solenoides (bobinas de Ruhmkorff semelhante a um transformador elevador), um capacitor e entre outros elementos. Nas extremidades da segunda solenoide, Hertz colocou duas esferas interligadas a duas placas (material condutor que possivelmente é o primeiro modelo de antena construído intencionalmente pelo homem) que gerava centelhas elétricas com um certo período de tempo conforme o SWITCH abria e fechava o circuito. Dessa forma ele aproximou um loop feito de fio condutor com outras duas esferas nas extremidades. Contudo baseando-se na argumentação de Maxwell e se suas teorias forem corretas e as ondas eletromagnéticas estiverem se espalhando, as mesmas iriam induzir uma corrente elétrica no loop e assim produziriam faíscas através das esferas do loop com o mesmo período de tempo das duas primeiras esferas [32][33].

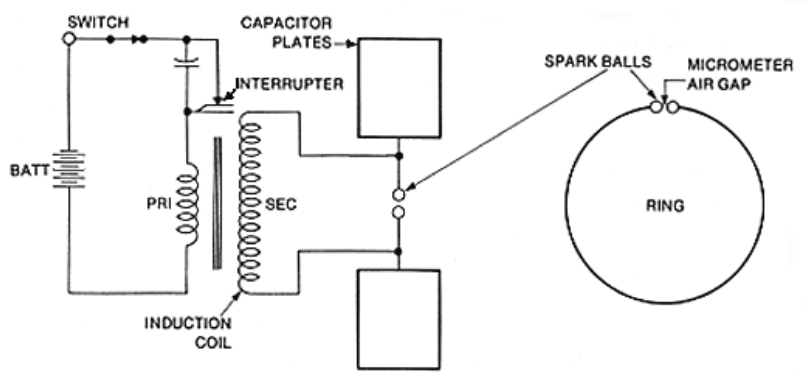

Fonte: Harvard, people seas. Configuração experimental do dipolo oscilante de Hertz [32]. 
Nos dias atuais graças às contribuições citadas acima, tem-se o conhecimento dos aspectos principais das ondas eletromagnéticas, onde as mesmas independem de um meio de propagação e possuem uma velocidade peculiar de movimentação constante dentro do mesmo meio, onde para o vácuo é de 299.792.458 [m/s], e semelhantemente às ondas mecânicas, as ondas eletromagnéticas possuem frequência e uma distância entre seus máximos e mínimos subsequentes, que denominamos de comprimento de onda, dado pela letra grega lambda $(\lambda)$.

Figura 2.6: A imagem genérica abaixo ilustra algumas características das ondas eletromagnéticas com a dependência entre os campos elétricos e magnéticos propostos por Maxwell e comprovada por Hertz.

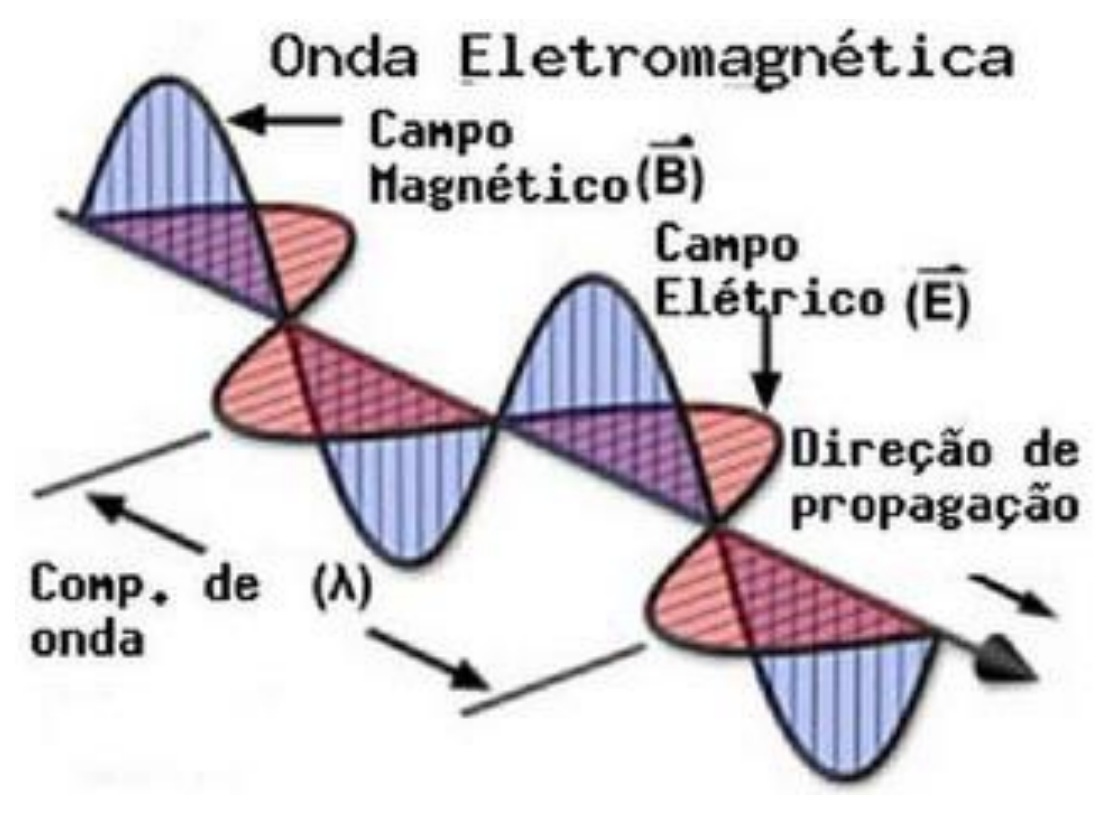

Fonte: Configuração experimental do dipolo oscilante de Hertz [34].

Em um sistema de geração, transmissão e recepção de ondas eletromagnéticas existem elementos fundamentais que constituem o mesmo. O estudo para esse sistema é essencial não somente para implementação na área de telecomunicação, mas também para instrumentação médica, astrofísica e assim como outros. Existem várias classificações de ondas eletromagnéticas conhecidas, dentre as quais podemos citar o raio X, raio gama e luz visível, que são exemplos de ondas geradas por fontes de nível atômico e até nucleares, que fazem parte de uma área mais complexa da física (física nuclear). No entanto, para uma descrição qualitativa de uma onda eletromagnética imagine um circuito oscilador LC ligado a uma fonte 
de alimentação onde é estabelecida uma frequência que depende dos parâmetros capacitivos e indutivos do circuito, tal frequência obedece à equação $\omega(=1 / \sqrt{L C})$ onde Ômega $(\omega)$ é a frequência angular do sistema [35].

Figura 2.7: A ilustração abaixo demonstra um circuito RLC ideal, onde temos um fluxo de corrente alternada nos terminais do secundário do transformador, que conectam duas hastes A1 e A2, de material condutor e dimensões especificas, onde para a metade de um ciclo a corrente flui para uma das hastes e para a outra metade do ciclo a corrente flui no sentindo oposto indo para a outra haste. Essa alternância na corrente produz um campo eletromagnético que se propaga com velocidade $\mathrm{C}$ e uma quantidade de ciclos por segundo, que denominamos de frequência $(f)$. $O$ espaçamento entre os máximos de cada ciclo, como já mencionado acima chamamos de lambda $(\lambda)$.

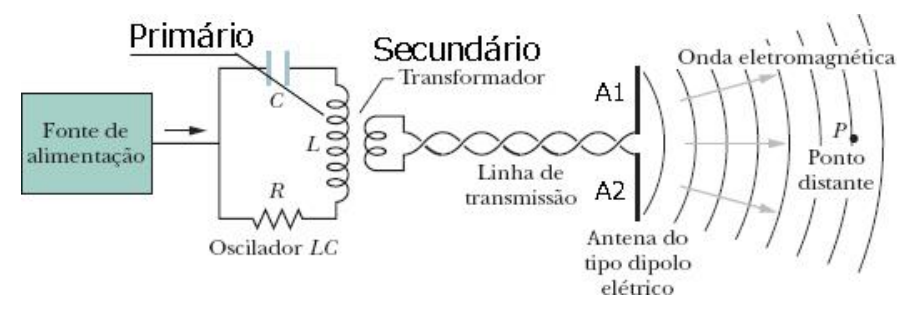

Fonte: Halliday, David, Fundamentos de física, volume 4 [35].

Existem outros circuitos similares que ao invés de produzir ondas eletromagnéticas, eles captam (recebem) os sinais ondulatórios. Tal circuito tem aplicações importantíssimas na evolução do conhecimento humano, como nos estudos que utilizam os microscópios ópticos e radiotelescópios. Contudo, tanto o dispositivo que emite quanto o que recebe tem como elemento comum uma antena.

No dicionário o significado de antenas é "Condutor elétrico empregado na telegrafia sem fios, na radiotelefonia, na radiofonia e na radiotelevisão, para facilitar a irradiação e a captação das ondas eletromagnéticas" [36]. Já o Institute of Electrical and Electronics Engineers (IEEE) define uma antena como "a parte de um sistema de transmissão ou recepção projetada para radiar ou receber ondas eletromagnéticas" ${ }^{[37]}$. Dessa forma pode-se entender que uma antena é feita de um material condutor que pode servir como emissor de ondas eletromagnéticas e trabalhar como receptor das mesmas. Existem diversos tipos de antenas, onde podem se citar alguns modelos como, Sloper, Windom, G5RV, W3DZZ, Bazuca, YagiUda, Loop, Vertical Marconi, Painel H (Duplo Delta), Parabólicas, Microfita, entre outras. Porém, qualquer material condutor permeado por uma onda eletromagnética pode servir de captador, tendo em vista que a onda possui duas componentes, uma elétrica e outra magnéticoa, ambas variante no tempo. Deste modo, é produzido uma corrente e tensão 
alternadas, nesse material, com a mesma frequência da onda incidente, como prevê a lei de Faraday, citada anteriormente ${ }^{[27][29]}$. Contudo, para uma boa performance na captação do sinal eletromagnético é essencial que o material condutor tenha pelo menos uma fração do comprimento de onda que se deseja captar, sendo o ideal que tal material tenha o comprimento de $\frac{\lambda}{2}$ para uma antena de meia onda e o cumprimento total $(\lambda)$ para uma antena de onda completa. O casamento de impedâncias também é de extrema importância, tendo como objetivo ter a máxima transferência de potência e evitar ondas estacionarias oriundas de interferências e reflexões do sinal. [38][39]

Antenas são estruturas condutoras capazes de irradiar ou receber ondas eletromagnéticas do meio ambiente de propagação, portanto, antenas possuem a função de intermediação entre a onda no espaço livre com as estruturas de guias de ondas. As antenas que atuam na transmissão são encarregadas pela formação do sinal radioelétrico irradiado ou transmitido. A antena receptora por outro lado tem a função de confinar a energia eletromagnética das ondas incidentes do espaço livre e direciona-la ao sistema de recepção. ${ }^{[40]}$

Figura 2.8: A imagem abaixo ilustra um enlace de radiocomunicação, com as antenas de transmissão e de recepção nas funções de emitir e de receber a onda eletromagnética.

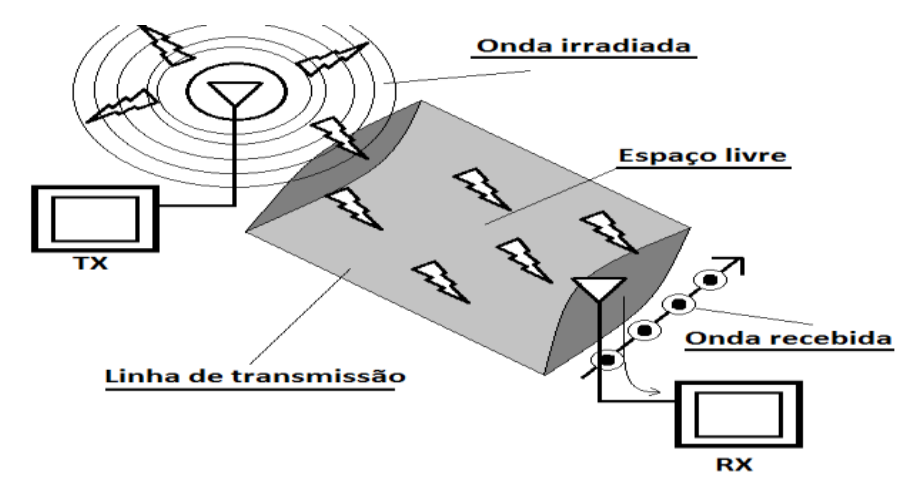

Fonte: autoria própria.

Existem diversos tipos e formas de antenas, de acordo com as características desejadas. Estão disponíveis desde estruturas simples como monopolos ou dipolos curtos, sejam de meia-onda ou onda completa, antenas em espiral, antenas helicoidais e etc. As antenas podem ser encontradas com características especiais, como na distribuição de energia para muitas direções. Podem ser estruturas com características de comportamentos aproximadamente estáveis em grandes larguras de banda ou que atuem como bloqueio para sinais indesejáveis, dessa maneira pode-se concluir que as especificações das antenas podem ser muito diferentes, conforme o objetivo, e assim deve-se ter previamente determinado os parâmetros para o 
desenvolvimento de uma antena. ${ }^{[40][41]}$ Desta forma, para o presente projeto foi desenvolvido uma antena de microfita, tendo em vista suas características físicas enquadrando-se nos prérequisitos necessários para o protótipo, juntamente com circuitos de retificação e dobrador de tensão.

\section{ANTENA DE MICROFITA}

As antenas de microfita são bastante usadas nos dias atuais em diversas áreas, tais como aeronáuticas, aeroespaciais, de satélites e rádios moveis. Tais antenas são discretas, versáteis, e adaptam-se a superfícies planas e não planas, são de fácil elaboração e baixo investimento, possuindo diversas formas, podendo ter uma estrutura resistente quando implementada em superfícies solidas.

A partir da década de 1970 as antenas de microfita obtiveram notória repercussão, muito embora, antes disso, em 1953 já houvesse relatos de uma antena de microfita e uma patente em 1955. As antenas de microfita, como mostrado na Figura 15, consistem em uma fina camada de material condutor, denominado plaqueta ou fita, possuindo as seguintes proporções $t<<\lambda_{0}$, onde $\lambda_{0}$ é o comprimento de onda no espaço livre, fixada a uma distância correspondente a uma pequena parte do comprimento de onda ( $h<<\lambda_{0}$, habitualmente $0,003 \lambda_{0} \leq h \leq 0,05 \lambda_{0}$ ) acima de um plano de terra. Usualmente, em geometrias retangulares, seu comprimento $L$ é tal que $\lambda_{0} / 3<L<\lambda_{0} / 2$. A fita e o plano de terra são separados por uma camada de material dielétrico de espessura $h$, tida como o substrato, como mostrado na figura abaixo.

Figura 3.1: A ilustração abaixo mostra graficamente o designer de uma antena de microfita retangular.

Fonte: Rocha.[42]

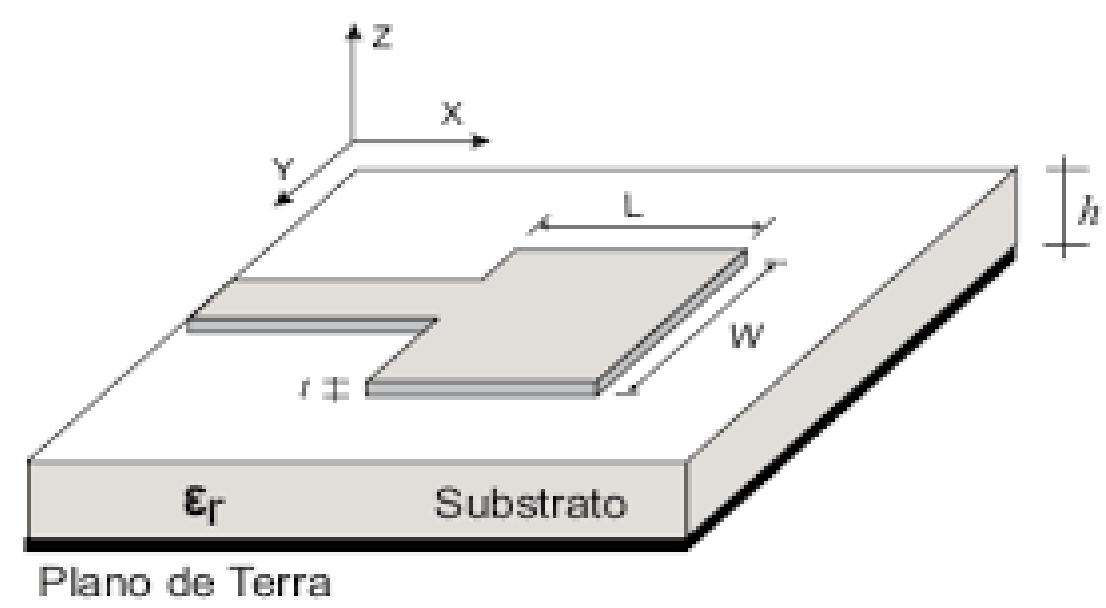


Existem diversos materiais que podem ser utilizados como substrato para o projeto de antenas de microfita. Habitualmente, utiliza-se constante dielétrica de valores que se enquadram entre $2,2 \leq \varepsilon_{r} \leq 12$. Para obter um bom desempenho nas antenas, os substratos mais adequados são espessos e têm constante dielétrica de pequeno valor, pois possuem maior eficácia, maior largura de banda e campos mais dispersos, facilitando a radiação no espaço. ${ }^{[43]}$

Substratos estreitos com constante dielétrica elevada são ideais para sistemas de micro-ondas, pois concatenam com melhor eficiência a onda incidente, entretanto, esses substratos possuem menor eficiência e larguras de banda mais estreitas. ${ }^{[43]}$ Como antenas de microfitas são geralmente acopladas com outros circuitos de micro-ondas, um equilíbrio deve ser buscado entre a antena e os demais circuitos promovendo assim um desempenho satisfatório.

\subsection{MODELOS DE PATCH E TÉCNICAS DE EXCITAÇÃO}

Existe uma infinidade de modelos de patch de antenas de microfita, assim como diversos modos de excitação dos mesmos, onde pode-se salientar a excitação pelo método de ponta de prova coaxial, linha de transmissão de microfita, proximidade eletromagnética, acoplamento por abertura, dentre outras. O método de linha de transmissão foi à forma de excitação utilizada para o presente projeto, não sendo a mais precisa, porém é a forma com menor peso computacional sendo a modelagem ideal para as condições da pesquisa.[44]

Em relação aos tipos de Patch, podem-se destacar algumas geometrias de elementos irradiados na figura 16.

Figura 3.2: Formas comuns de geometrias adotadas para elementos irradiadores de antenas de microfita.

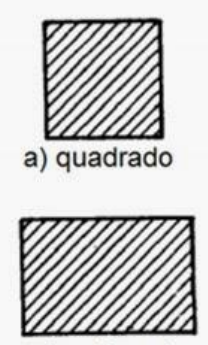

d) retângulo

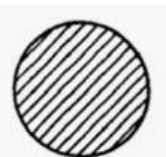

b) círculo

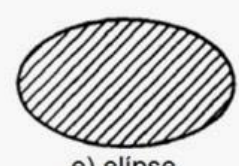

e) elipse

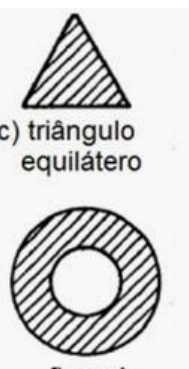

f) anel

Fonte: NightWire Enginnering. ${ }^{[45]}$ 
A forma geométrica adotada para realização da pesquisa foi a retangular por ser de fácil fabricação e casamento de impedância. As antenas de geometria retangular se adequam melhor as superfícies e economizam material.

\subsection{MODELAGEM}

O sistema de modelagem para a antena de microfita retangular dar-se por intermédio de equações matemáticas e métodos simulatórios que permitam variar determinados parâmetros da antena até um resultado satisfatório de dimensões. A seguir, uma lista de equações utilizadas para calcular os devidos parâmetros da antena tendo como base os critérios preestabelecidos.

Para o cálculo da espessura do substrato

$$
h=0,05 \lambda_{0}
$$

Sendo que.

$$
\lambda_{0}=\frac{C}{f_{r}}
$$

Onde $c$ é a velocidade da luz no espaço livre e $f_{r}$ é a frequência de ressonância Substituindo na Eq.12 com a Eq. 13 temos:

$$
h=\frac{0,05 C}{f_{r}}=[\mathrm{mm}]
$$

Para o cálculo do $w$ utiliza-se uma forma que leva em consideração a velocidade da luz no vácuo e o dielétrico do meio.

$$
w=\frac{1}{2 f_{r} \sqrt{\mu_{0} \varepsilon_{0}}} \sqrt{\frac{2}{\varepsilon_{r}+1}}
$$

Ao escolher o material dielétrico do substrato faz-se necessário ajustar o valor do mesmo, pois as linhas de campo que se espraiam acabam passando por outro dielétrico podendo ser ar ou qualquer outro tipo de material, logo deve-se ajustar e compensar as geometrias da antena para um tamanho apropriado considerando as linhas de campo que não concatenam na antena. Desta forma, passam a ser utilizados nos cálculos um dielétrico efetivo $\varepsilon_{e f f}$ que leva em consideração o contato das linhas de campo com outro dielétrico. O valor da 
frequência é inversamente proporcional ao espraiamento das ondas sendo que quanto maior a frequência menos efeitos de bordas se tem, e assim o $\varepsilon_{e f f}$ se aproxima do valor real do dielétrico do substrato.

Para calcular o dielétrico efetivo $\varepsilon_{e f f}$ temos:

$$
\varepsilon_{r e f}=\frac{\varepsilon_{r}+1}{2}+\left(\frac{\varepsilon_{r}-1}{2}\right) *\left(1+\frac{12 h}{w}\right)^{-\frac{1}{2}}
$$

Tendo calculado o $\varepsilon_{r e f}, h e w$ podemos efetuar a operação para o ajuste devido ao efeito de espraiamento das linhas.

$$
\frac{\Delta L}{h}=0,412\left(\frac{\left(\left(\varepsilon_{r e f}+0,3\right)\left(\frac{W}{h}+0,264\right)\right)}{\left(\varepsilon_{r e f}-0,258\right)\left(\frac{W}{h}+0,8\right)}\right)
$$

Figura 3.3: A imagem abaixa exemplifica o comprimento físico e efetivo de uma plaqueta retangular.

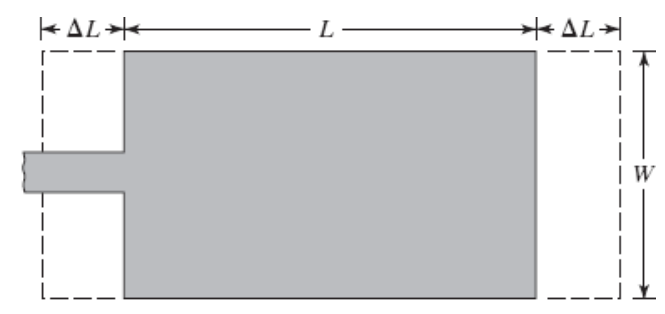

(a) Vista superior

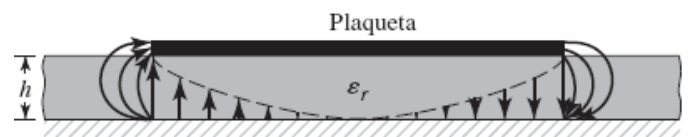

Fonte: Ballanis.[43]

(b) Vista lateral

E finalmente o verdadeiro valor da plaqueta é dado pela expressão:

$$
L=\frac{c}{2 f_{r} \sqrt{\varepsilon_{r}}}-2 \Delta L
$$

Vale ressaltar que para o projeto de uma antena de microfita, alguns parâmetros precisam ser previamente determinados, entre eles; frequência de ressonância, espessura do substrato, espessura do patch e tipo do substrato. 


\section{ARRANJO DE ANTENAS}

Estabelece-se como arranjo de antenas, o acoplamento de múltiplas antenas, que após um conveniente agrupamento deverão integrar suas parcelas de campos irradiados ou recebidos, aumentando sua eficiência quer seja ao transmitir ou receber assim como na ampliação do ganho e sua banda de operação. O conceito de agrupamentos de várias antenas é mundialmente difundido como beamforming, dando advento das intituladas antenas inteligentes.[46]

Os arranjos de antenas são compostos por uma quantidade finita de antenas similares onde os sinais induzidos são sobrepostos formando a saída do arranjo. Cada elemento do arranjo é formado por uma antena individual. Características como o ganho máximo do arranjo podem ser controladas pelo ajuste da fase do sinal irradiante entre os distintos elementos.

Individualmente cada elemento contribui com baixos níveis de efetividade e força de sinal, deste modo, uma solução para este problema é a utilização de arranjos de antenas, onde na maioria dos casos as mesmas são dispostas em formação linear, planar/matricial. Nas figuras 4.1 e 4.2 são ilustrados dois arranjos um linear e outro planar/matricial.

Na Figura 4.1: Está imagem abaixa ilustra um arranjo linear com quatro elementos similares e com espaçamento igual entre os seus elementos subsequentes.

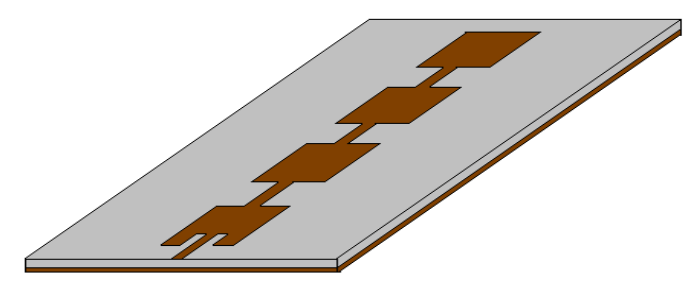

Fonte: Caetano.[47]

Figura 4.2: Na imagem abaixo apresenta-se um arranjo planar de uma antena de microfita. Esta configuração também pode ser encontrada nas literaturas como arranjo matricial.

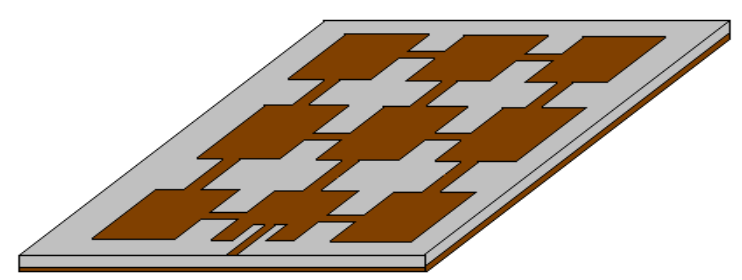

Fonte: Caetano.[47] 


\section{ENERGY HARVESTING}

Energy harvesting (colheita de energia) é habitualmente definida como a conversão de energia ambiental em eletricidade. Podemos definir a coleta de energia como "a obtenção e armazenamento de energia do meio ambiente para uso off-grid". Existem diversas formas de energia contidas no meio ambiente: térmica, química, elétrica, mecânica entre outras.[12][48]

Para usufruirmos da colheita de energia, faz-se necessário ter disponível uma ou mais destas fontes no ambiente de interesse, assim como a existência de um transdutor específico para converter a energia em análise em eletricidade, neste caso utilizamos antenas retificadoras - Rectenna com a finalidade de obter energia elétrica do meio. A coleta de energia pode explorar diferentes fontes, como energia solar, vento, vibrações mecânicas, variações de temperatura, campos magnéticos, etc. Este trabalho concentra seus esforços na coleta de energia de radiofrequência - RF onde tem como objetivo converter as ondas de rádio na faixa de micro-ondas em corrente contínua e armazená-las em uma bateria. O dispositivo rectenna utilizado para confinar as ondas eletromagnéticas e converte-las em corrente contínua é dividido em três blocos principais. O primeiro é constituído da antena receptora, que tem a função de captar o sinal de RF do espaço com a finalidade de alimentação dos próximos sistemas. ${ }^{[49]} \mathrm{O}$ segundo subsistema é formado por um filtro passa banda para auxiliar a antena na discriminação do sinal e evitar sobreposição destrutiva do sinal. O terceiro bloco é constituído do circuito de retificação, fazendo uso de um diodo schottky que tem alto nível de comutação. Tal sistema tem a função de converter o sinal AC obtido da antena para sinal DC de forma eficiente. A imagem abaixo exemplifica a sequência dos sistemas da rectenna. ${ }^{[50]}$

Figura 5.1: Diagrama sequencial dos blocos principais de uma rectenna.

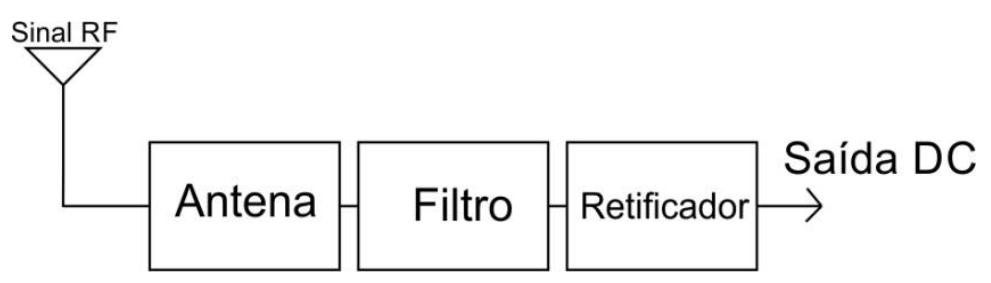

Fonte: Própria. 


\section{CASAMENTO DE IMPEDÂNCIAS}

Nos projetos de radiofrequência um dos pré-requisitos é a obtenção de uma excelente transmissão de sinal entre suas etapas. Essa eficiência é verificada por meio de uma maximização da potência transferida e/ou na minimização dos sinais refletidos no decorrer da transmissão.

Para adquirir o melhor aproveitamento nos circuitos de aparelhos de radiofrequência faz-se necessário ter uma relação específica entre as impedâncias dos blocos dos sistemas, ou seja, de saída do estágio emissor e a impedância de entrada e o estágio receptor. Quando essas impedâncias não estão balanceadas do modo esperado, chamamos esse estado de descasamento de impedância, sendo necessária então, a utilização de métodos de casamento, para aprimorar esse ajuste. Entretanto, ao atender as condições desejadas, denominamos de casamento de impedância entre a fonte (antena) e a carga.

Para as antenas de microfita, cada forma de excitação do patch possui características particulares para o casamento de impedâncias entre a fonte e o elemento irradiante. No presente estudo foi realizado o método de linha de transmissão, sendo que os mecanismos para o casamento de impedâncias mais utilizadas são: por deslocamento; transformador de um quarto de onda e inset-fed. Sendo que, estudos realizados demostram que o melhor casamento de impedância advem da junção de vários métodos. [51]

O método do transformador de $1 / 4$ de onda realiza o estreitamento da linha de transmissão, de forma que, em determinados casos a geometria do projeto torna-se de difícil implementação. A técnica do inset-fed insere cortes no elemento irradiante, modificando a geometria da antena.

\section{METODOLOGIA}

Para o desenvolvimento do protótipo, assim como as etapas do relatório da pesquisa, uma série de processos foram efetuados, buscando alcançar os objetivos propostos no início da pesquisa. Iniciando-se com as revisões bibliográficas relacionadas com o tema que possibilitarama uma maior compreensão dos fenômenos físicos, realização de parcerias com a ANATEL e a Escola de Comunicação do Exército - ESCOM, escolha de estruturas fundamentais para o protótipo, como a carga a ser alimentada e os parâmetros do meio ambiente a serem observados, assim como a aquisição de materiais necessários para o desenvolvimento do protótipo. 
Através de parcerias foi possível realizar uma análise do ambiente de implementação. Ao fazer uso do banco de dados fornecidos pela Anatel, foi escolhida uma fonte de energia ideal para a pesquisa com base no nível energético, disponibilidade e proximidade da fonte. Com a ESCOM foi possível avaliar melhor a geometria de antenas de microfita, verificação das medidas de comprimento e espessura com encaixes adequados para os equipamentos de medição.

Uma vez determinada à fonte a ser utilizada, passou-se ao desenvolvimento da escolha do tipo da antena, filtro, diodo e software para simulação. Com a determinação do tipo da antena, o próximo passo foi formular os critérios para a simulação da mesma. Foi desenvolvido um código em um software voltado para cálculos onde estabeleceu-se os parâmetros iniciais para simulação, assim como dados da impedância de entrada da antena. Softwares de simulação de circuitos foram utilizados para um ajuste fino nos parâmetros e casamento de impedância, tanto da linha de transmissão da antena com a carga de 50ohms quanto para a formulação dos circuitos de dobrador de tensão e retificação.

Por fim, os testes das simulações do protótipo, com os resultados serão apresentados por meios de gráficos e tabelas nos itens seguintes, juntamente com o detalhamento da metodologia da presente pesquisa.

\section{DESCRIÇÃO DO SISTEMA PROPOSTO}

Esta seção apresenta maiores detalhes do desenvolvimento dos parâmetros do projeto e obtenção dos dados para simulação em software.

\subsection{ESTAÇÕES DO SMP (CELULAR 2G, 3G E 4G)}

Fazendo uso do banco de dados disponibilizado pela agência nacional de telecomunicações - Anatel, foi possível visualizar as localizações das estações de telefonia móvel, bem como suas características de faixa de frequência, nível de potência do sinal e altura das antenas. 
Figura 8.1: Estações selecionadas das operadoras Claro S.A, Tim S.A, TELEFÔNICA BRASIL S.A, OI móvel.

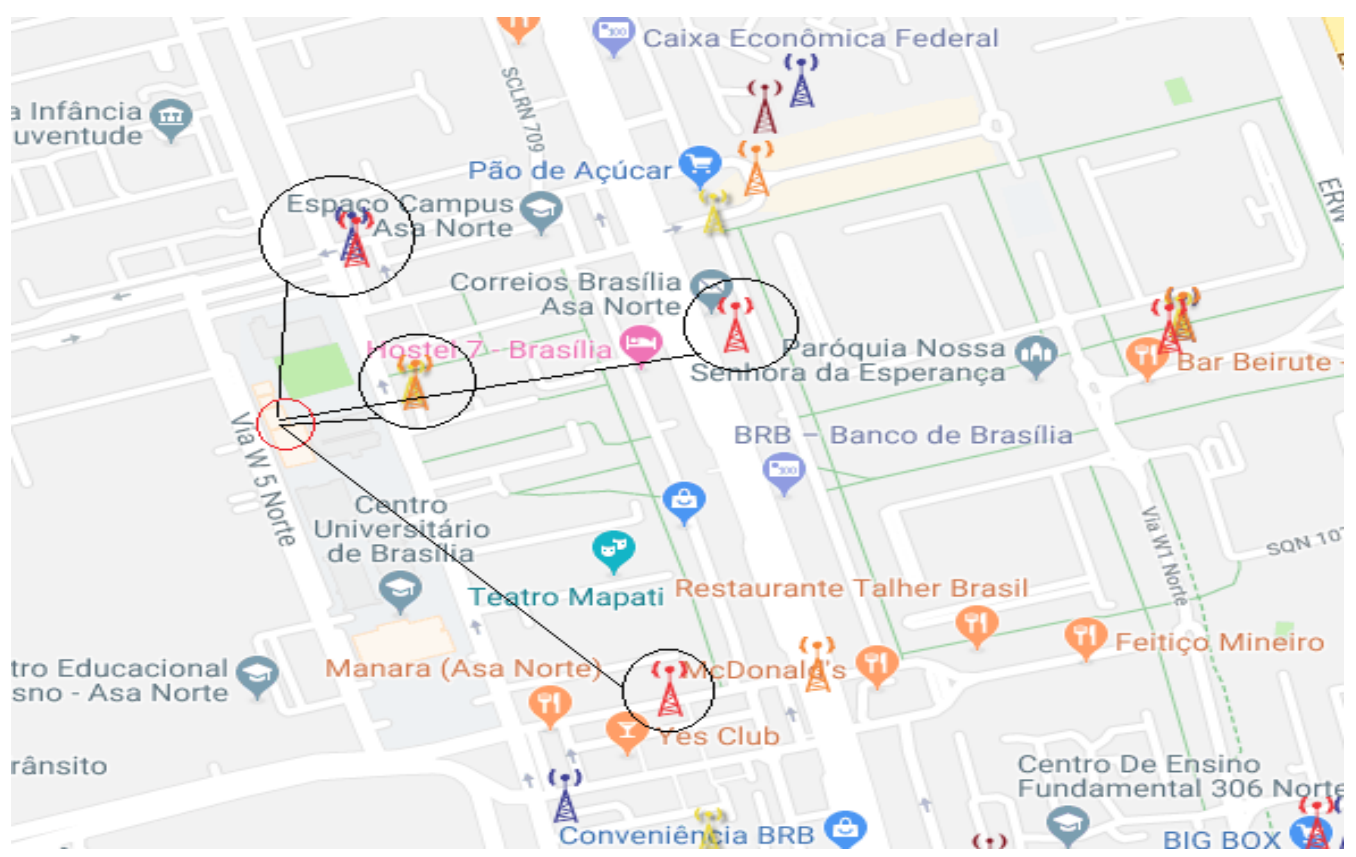

Fonte: Telebrasil [52].

A seguir estão dispostas tabelas (1 a 5) com as localizações das estações de telefonia móvel diferenciadas por suas latitudes e longitudes. As alturas das antenas variam entre $15 \mathrm{~m}$ a $26 \mathrm{~m}$, sendo em sua maioria fontes que trabalham com dispositivos em arranjo.

TABELA 1 - Lista das operadoras de telefonia móvel homologadas nas proximidades da área de implementação do projeto - TELEFÔNICA: Quadra SHCGN 708 Bloco K,S/N,Asa Norte; OI MÓVEl: SHCGN 708 BLOCO K,S/N${ }^{\circ}$,ASA NORTE , LATITUDE: 15S455640, LONGITUDE: 47W533520 : Campus da Asa Norte: SEPN 707/907 - Campus Universitário.

\begin{tabular}{llllll}
\hline Entidade & $\begin{array}{l}\text { Num. } \\
\text { Estação }\end{array}$ & Freq. Inicial (Hz) & Freq. Final (Hz) & $\begin{array}{l}\text { Altura Antena } \\
(\mathbf{m})\end{array}$ & $\begin{array}{l}\text { Potência Transm. } \\
(\mathbf{W})\end{array}$ \\
\hline TELEFÔNICA & $1,001 \mathrm{E}+09$ & 185.000 .000 .000 & 186.000 .000 .000 & 25 & 40.0 \\
TELEFÔNICA & $1,001 \mathrm{E}+09$ & 185.000 .000 .000 & 186.000 .000 .000 & 25 & 40.0 \\
TELEFÔNICA & $1,001 \mathrm{E}+09$ & 185.000 .000 .000 & 186.000 .000 .000 & 25 & 40.0 \\
TELEFÔNICA & $1,001 \mathrm{E}+09$ & 267.000 .000 .000 & 269.000 .000 .000 & 20.0 & 30.000 \\
TELEFÔNICA & $1,001 \mathrm{E}+09$ & 267.000 .000 .000 & 269.000 .000 .000 & 20.0 & 30.000 \\
TELEFÔNICA & $1,001 \mathrm{E}+09$ & 215.500 .000 .000 & 216.500 .000 .000 & 20.0 & 40.000 \\
TELEFÔNICA & $1,001 \mathrm{E}+09$ & 215.500 .000 .000 & 216.500 .000 .000 & 20.0 & 40.000 \\
TELEFÔNICA & $1,001 \mathrm{E}+09$ & 267.000 .000 .000 & 269.000 .000 .000 & 20.0 & 30.000 \\
TELEFÔNICA & $1,001 \mathrm{E}+09$ & 215.500 .000 .000 & 216.500 .000 .000 & 20.0 & 40.000 \\
OI MÓVEL S.A. & 689602871 & 183.500 .000 .000 & 185.000 .000 .000 & 19.0 & 52.000 \\
OI MÓVEL S.A. & 689602871 & 183.500 .000 .000 & 185.000 .000 .000 & 19.0 & 52.000 \\
OI MÓVEL S.A. & 689602871 & 183.500 .000 .000 & 185.000 .000 .000 & 19.0 & 49.100 \\
OI MÓVEL S.A. & 689602871 & 183.500 .000 .000 & 185.000 .000 .000 & 19.0 & 49.100 \\
OI MÓVEL S.A. & 689602871 & 183.500 .000 .000 & 185.000 .000 .000 & 19.0 & 49.100 \\
OI MÓVEL S.A. & 689602871 & 183.500 .000 .000 & 185.000 .000 .000 & 19.0 & 37.500 \\
OI MÓVEL S.A. & 689602871 & 183.500 .000 .000 & 185.000 .000 .000 & 19.0 & 52.000 \\
OI MÓVEL S.A. & 689602871 & 183.500 .000 .000 & 185.000 .000 .000 & 19.0 & 52.000
\end{tabular}




$\begin{array}{llllll}\text { OI MÓVEL S.A. } & 689602871 & 183.500 .000 .000 & 185.000 .000 .000 & 19.0 & 49.100 \\ \text { OI MÓVEL S.A. } & 689602871 & 183.500 .000 .000 & 185.000 .000 .000 & 19.0 & 37.500 \\ \text { OI MÓVEL S.A. } & 689602871 & 211.000 .000 .000 & 212.500 .000 .000 & 19.0 & 49.100 \\ \text { OI MÓVEL S.A. } & 689602871 & 211.000 .000 .000 & 212.500 .000 .000 & 19.0 & 49.100\end{array}$

Fonte: MOSAICO - Sistema Integrado de Gestão e Controle do Espectro

TABELA 2 - Lista das operadoras de telefonia móvel homologadas nas proximidades da área de implementação do projeto - CLARO S.A: SETOR SCRN 708/709 BLOCO "E" ENTRADA 28, S/N, ASA NORTE, LATITUDE: 15S455029; LONGITUDE: 47W533721 : Campus da Asa Norte: SEPN 707/907 - Campus Universitário.

\begin{tabular}{|c|c|c|c|c|c|}
\hline Entidade & $\begin{array}{l}\text { Num. } \\
\text { Estação }\end{array}$ & Freq. Inicial (Hz) & Freq. Final $(\mathrm{Hz})$ & $\begin{array}{l}\text { Altura Antena } \\
\text { (m) }\end{array}$ & $\begin{array}{l}\text { Potência Transm. } \\
\text { (W) }\end{array}$ \\
\hline CLARO S.A. & $1,001 \mathrm{E}+09$ & 212.500 .000 .000 & $2,14 \mathrm{E}+11$ & 20.0 & 81.85 \\
\hline CLARO S.A. & $1,001 \mathrm{E}+09$ & 212.500 .000 .000 & $2,14 \mathrm{E}+11$ & 20.0 & 81.85 \\
\hline CLARO S.A. & $1,001 \mathrm{E}+09$ & 88.000 .000 .000 & 89000000000 & 20.0 & 60.0 \\
\hline CLARO S.A. & $1,001 \mathrm{E}+09$ & 88.000 .000 .000 & 89000000000 & 20.0 & 60.0 \\
\hline CLARO S.A. & $1,001 \mathrm{E}+09$ & 212.500 .000 .000 & $2,14 \mathrm{E}+11$ & 20.0 & 81.85 \\
\hline CLARO S.A. & $1,001 \mathrm{E}+09$ & 88.000 .000 .000 & 89000000000 & 20.0 & 60.0 \\
\hline CLARO S.A. & $1,001 \mathrm{E}+09$ & 88.000 .000 .000 & 89000000000 & 20.0 & 60.0 \\
\hline CLARO S.A. & $1,001 \mathrm{E}+09$ & 212.500 .000 .000 & $2,14 \mathrm{E}+11$ & 20.0 & 81.85 \\
\hline CLARO S.A. & $1,001 \mathrm{E}+09$ & 212.500 .000 .000 & $2,14 \mathrm{E}+11$ & 20.0 & 81.85 \\
\hline CLARO S.A. & $1,001 \mathrm{E}+09$ & 212.500 .000 .000 & $2,14 \mathrm{E}+11$ & 20.0 & 81.85 \\
\hline CLARO S.A. & $1,001 \mathrm{E}+09$ & 88.000 .000 .000 & 89000000000 & 20.0 & 60.0 \\
\hline CLARO S.A. & $1,001 \mathrm{E}+09$ & 88.000 .000 .000 & 89000000000 & 20.0 & 60.0 \\
\hline CLARO S.A. & $1,001 \mathrm{E}+09$ & 89.150 .000 .000 & 89400000000 & 20.0 & 60.0 \\
\hline CLARO S.A. & $1,001 \mathrm{E}+09$ & 89.150 .000 .000 & 89400000000 & 20.0 & 60.0 \\
\hline CLARO S.A. & $1,001 \mathrm{E}+09$ & 89.150 .000 .000 & 89400000000 & 20.0 & 60.0 \\
\hline CLARO S.A. & $1,001 \mathrm{E}+09$ & 89.150 .000 .000 & 89400000000 & 20.0 & 60.0 \\
\hline CLARO S.A. & $1,001 \mathrm{E}+09$ & 89.150 .000 .000 & 89400000000 & 20.0 & 60.0 \\
\hline CLARO S.A. & $1,001 \mathrm{E}+09$ & 89.150 .000 .000 & 89400000000 & 20.0 & 60.0 \\
\hline CLARO S.A. & $1,001 \mathrm{E}+09$ & 263.000 .000 .000 & $2,65 \mathrm{E}+11$ & 20.0 & 40.0 \\
\hline CLARO S.A. & $1,001 \mathrm{E}+09$ & 263.000 .000 .000 & $2,65 E+11$ & 20.0 & 40.0 \\
\hline CLARO S.A. & $1,001 \mathrm{E}+09$ & 263.000 .000 .000 & $2,65 \mathrm{E}+11$ & 20.0 & 40.0 \\
\hline CLARO S.A. & $1,001 \mathrm{E}+09$ & 182.000 .000 .000 & $1,83 \mathrm{E}+11$ & 20.0 & 40.0 \\
\hline CLARO S.A. & $1,001 \mathrm{E}+09$ & 187.000 .000 .000 & $1,88 \mathrm{E}+11$ & 20.0 & 40.0 \\
\hline CLARO S.A. & $1,001 \mathrm{E}+09$ & 182.000 .000 .000 & $1,83 \mathrm{E}+11$ & 20.0 & 40.0 \\
\hline CLARO S.A. & $1,001 \mathrm{E}+09$ & 187.000 .000 .000 & $1,88 \mathrm{E}+11$ & 20.0 & 40.0 \\
\hline CLARO S.A. & $1,001 \mathrm{E}+09$ & 182.000 .000 .000 & $1,83 \mathrm{E}+11$ & 20.0 & 40.0 \\
\hline CLARO S.A. & $1,001 \mathrm{E}+09$ & 187.000.000.000 & $1,88 \mathrm{E}+11$ & 20.0 & 40.0 \\
\hline CLARO S.A. & $1,001 \mathrm{E}+09$ & 79.300 .000 .000 & 80300000000 & 20.0 & 60.0 \\
\hline CLARO S.A. & $1,001 \mathrm{E}+09$ & 79.300 .000 .000 & 80300000000 & 20.0 & 60.0 \\
\hline CLARO S.A. & $1,001 \mathrm{E}+09$ & 79.300 .000 .000 & 80300000000 & 20.0 & 60.0 \\
\hline
\end{tabular}

Fonte: MOSAICO - Sistema Integrado de Gestão e Controle do Espectro

TABELA 3 - Lista das operadoras de telefonia móvel homologadas nas proximidades da área de implementação do projeto - CLARO S.A: RUA SEPN, 508 BL C , null, LATITUDE: 15S455393, LONGITUDE: 47W532457 : Campus da Asa Norte: SEPN 707/907 - Campus Universitário.

\begin{tabular}{llllll}
\hline Entidade & $\begin{array}{l}\text { Num. } \\
\text { Estação }\end{array}$ & Freq. Inicial (Hz) & Freq. Final (Hz) & $\begin{array}{l}\text { Altura Antena } \\
(\mathbf{m})\end{array}$ & $\begin{array}{l}\text { Potência Transm. } \\
\text { (W) }\end{array}$ \\
\hline CLARO S.A. & $1,005 \mathrm{E}+09$ & 212.500 .000 .000 & 213.500 .000 .000 & 10.0 & 5.0 \\
CLARO S.A. & $1,005 \mathrm{E}+09$ & 263.000 .000 .000 & 265.000 .000 .000 & 10.0 & 5.0 \\
\hline
\end{tabular}

Fonte: MOSAICO - Sistema Integrado de Gestão e Controle do Espectro

TABELA 4 - Lista das operadoras de telefonia móvel homologadas nas proximidades da área de implementação do projeto - CLARO S.A: Quadra SCRN 706/707 Bloco G,S/N,Asa Norte, LATITUDE: 15S460948, LONGITUDE: 47W532749 : Campus da Asa Norte: SEPN 707/907 Campus Universitário.

\begin{tabular}{llllll}
\hline Entidade & $\begin{array}{l}\text { Num. } \\
\text { Estação }\end{array}$ & Freq. Inicial (Hz) & Freq. Final (Hz) & $\begin{array}{l}\text { Altura Antena } \\
(\mathbf{m})\end{array}$ & $\begin{array}{l}\text { Potência Transm. } \\
(\mathbf{W})\end{array}$ \\
\hline CLARO S.A. & $1,003 \mathrm{E}+09$ & 212.500 .000 .000 & 213.500 .000 .000 & 15.0 & 62.8
\end{tabular}




\begin{tabular}{|c|c|c|c|c|c|}
\hline CLARO S.A. & $1,003 \mathrm{E}+09$ & 212.500 .000 .000 & 213.500 .000 .000 & 15.0 & 62.8 \\
\hline CLARO S.A. & $1,003 \mathrm{E}+09$ & 88.000 .000 .000 & 89.000 .000 .000 & 15.0 & 66.2 \\
\hline CLARO S.A. & $1,003 \mathrm{E}+09$ & 263.000 .000 .000 & 265.000 .000 .000 & 15.0 & 40.0 \\
\hline CLARO S.A. & $1,003 \mathrm{E}+09$ & 263.000 .000 .000 & 265.000 .000 .000 & 15.0 & 80.0 \\
\hline CLARO S.A. & $1,003 \mathrm{E}+09$ & 263.000 .000 .000 & 265.000 .000 .000 & 15.0 & 40.0 \\
\hline CLARO S.A. & $1,003 \mathrm{E}+09$ & 263.000 .000 .000 & 265.000 .000 .000 & 15.0 & 80.0 \\
\hline CLARO S.A. & $1,003 \mathrm{E}+09$ & 263.000 .000 .000 & 265.000 .000 .000 & 15.0 & 40.0 \\
\hline CLARO S.A. & $1,003 \mathrm{E}+09$ & 212.500 .000 .000 & 213.500 .000 .000 & 15.0 & 62.8 \\
\hline CLARO S.A. & $1,003 \mathrm{E}+09$ & 212.500 .000 .000 & 213.500 .000 .000 & 15.0 & 62.8 \\
\hline CLARO S.A. & $1,003 \mathrm{E}+09$ & 182.000 .000 .000 & 182.250 .000 .000 & 15.0 & 40.0 \\
\hline CLARO S.A. & $1,003 \mathrm{E}+09$ & 182.000 .000 .000 & 182.250 .000 .000 & 15.0 & 40.0 \\
\hline CLARO S.A. & $1,003 \mathrm{E}+09$ & 182.250 .000 .000 & 182.500 .000 .000 & 15.0 & 40.0 \\
\hline CLARO S.A. & $1,003 \mathrm{E}+09$ & 88.000 .000 .000 & 89.000 .000 .000 & 15.0 & 66.2 \\
\hline CLARO S.A. & $1,003 \mathrm{E}+09$ & 88.000 .000 .000 & 89.000 .000 .000 & 15.0 & 60.0 \\
\hline CLARO S.A. & $1,003 \mathrm{E}+09$ & 187.000 .000 .000 & 188.000 .000 .000 & 15.0 & 40.0 \\
\hline CLARO S.A. & $1,003 \mathrm{E}+09$ & 212.500 .000 .000 & 213.500 .000 .000 & 15.0 & 62.8 \\
\hline CLARO S.A. & $1,003 \mathrm{E}+09$ & 212.500 .000 .000 & 213.500 .000 .000 & 15.0 & 62.8 \\
\hline CLARO S.A. & $1,003 \mathrm{E}+09$ & 182.250 .000 .000 & 182.500 .000 .000 & 15.0 & 40.0 \\
\hline CLARO S.A. & $1,003 \mathrm{E}+09$ & 88.000 .000 .000 & 89.000 .000 .000 & 15.0 & 60.0 \\
\hline CLARO S.A. & $1,003 \mathrm{E}+09$ & 88.000 .000 .000 & 89.000 .000 .000 & 15.0 & 66.2 \\
\hline CLARO S.A. & $1,003 \mathrm{E}+09$ & 88.000 .000 .000 & 89.000 .000 .000 & 15.0 & 60.0 \\
\hline CLARO S.A. & $1,003 \mathrm{E}+09$ & 187.000 .000 .000 & 188.000 .000 .000 & 15.0 & 40.0 \\
\hline CLARO S.A. & $1,003 \mathrm{E}+09$ & 263.000 .000 .000 & 265.000 .000 .000 & 15.0 & 80.0 \\
\hline CLARO S.A. & $1,003 \mathrm{E}+09$ & 182.000 .000 .000 & 182.250 .000 .000 & 26.0 & 40.0 \\
\hline CLARO S.A. & $1,003 \mathrm{E}+09$ & 182.000 .000 .000 & 182.250 .000 .000 & 26.0 & 40.0 \\
\hline CLARO S.A. & $1,003 \mathrm{E}+09$ & 182.250 .000 .000 & 182.500 .000 .000 & 26.0 & 40.0 \\
\hline CLARO S.A. & $1,003 \mathrm{E}+09$ & 182.250 .000 .000 & 182.500 .000 .000 & 26.0 & 40.0 \\
\hline CLARO S.A. & $1,003 \mathrm{E}+09$ & 187.000 .000 .000 & 188.000 .000 .000 & 26.0 & 40.0 \\
\hline CLARO S.A. & $1,003 \mathrm{E}+09$ & 187.000 .000 .000 & 188.000 .000 .000 & 26.0 & 40.0 \\
\hline CLARO S.A. & $1,003 \mathrm{E}+09$ & 182.000 .000 .000 & 182.250 .000 .000 & 26.0 & 40.0 \\
\hline CLARO S.A. & $1,003 \mathrm{E}+09$ & 182.000 .000 .000 & 182.250 .000 .000 & 26.0 & 40.0 \\
\hline CLARO S.A. & $1,003 \mathrm{E}+09$ & 182.250 .000 .000 & 182.500 .000 .000 & 26.0 & 40.0 \\
\hline CLARO S.A. & $1,003 \mathrm{E}+09$ & 182.250 .000 .000 & 182.500 .000 .000 & 26.0 & 40.0 \\
\hline CLARO S.A. & $1,003 \mathrm{E}+09$ & 187.000 .000 .000 & 188.000 .000 .000 & 26.0 & 40.0 \\
\hline CLARO S.A. & $1,003 \mathrm{E}+09$ & 187.000 .000 .000 & 188.000 .000 .000 & 26.0 & 40.0 \\
\hline CLARO S.A. & $1,003 \mathrm{E}+09$ & 182.000 .000 .000 & 182.250 .000 .000 & 15.0 & 40.0 \\
\hline CLARO S.A. & $1,003 \mathrm{E}+09$ & 182.000 .000 .000 & 182.250 .000 .000 & 15.0 & 40.0 \\
\hline CLARO S.A. & $1,003 \mathrm{E}+09$ & 182.250 .000 .000 & 182.500 .000 .000 & 15.0 & 40.0 \\
\hline CLARO S.A. & $1,003 \mathrm{E}+09$ & 182.250 .000 .000 & 182.500 .000 .000 & 15.0 & 40.0 \\
\hline CLARO S.A. & $1,003 \mathrm{E}+09$ & 187.000 .000 .000 & 188.000 .000 .000 & 15.0 & 40.0 \\
\hline CLARO S.A. & $1,003 \mathrm{E}+09$ & 187.000 .000 .000 & 188.000 .000 .000 & 15.0 & 40.0 \\
\hline CLARO S.A. & $1,003 \mathrm{E}+09$ & 182.000 .000 .000 & 182.250 .000 .000 & 15.0 & 40.0 \\
\hline CLARO S.A. & $1,003 \mathrm{E}+09$ & 182.000 .000 .000 & 182.250 .000 .000 & 15.0 & 40.0 \\
\hline CLARO S.A. & $1,003 \mathrm{E}+09$ & 182.250 .000 .000 & 182.500 .000 .000 & 15.0 & 40.0 \\
\hline CLARO S.A. & $1,003 \mathrm{E}+09$ & 182.250 .000 .000 & 182.500 .000 .000 & 15.0 & 40.0 \\
\hline CLARO S.A. & $1,003 \mathrm{E}+09$ & 187.000 .000 .000 & 188.000 .000 .000 & 15.0 & 40.0 \\
\hline CLARO S.A. & $1,003 \mathrm{E}+09$ & 187.000 .000 .000 & 188.000 .000 .000 & 15.0 & 40.0 \\
\hline CLARO S.A. & $1,003 \mathrm{E}+09$ & 182.000 .000 .000 & 182.250 .000 .000 & 26.0 & 40.0 \\
\hline CLARO S.A. & $1,003 \mathrm{E}+09$ & 182.000 .000 .000 & 182.250 .000 .000 & 26.0 & 40.0 \\
\hline
\end{tabular}

Fonte: MOSAICO - Sistema Integrado de Gestão e Controle do Espectro

TABELA 5 - Lista das operadoras de telefonia móvel homologadas nas proximidades da área de implementação do projeto - TIM S/A: SCRN, n 708/709 Bloco E, Entrada 44, LATITUDE: 15S455000, LONGITUDE: 47W532749 : Campus da Asa Norte: SEPN 707/907 - Campus Universitário.

\begin{tabular}{llllll}
\hline Entidade & $\begin{array}{l}\text { Num. } \\
\text { Estação }\end{array}$ & Freq. Inicial (Hz) & Freq. Final (Hz) & $\begin{array}{l}\text { Altura Antena } \\
(\mathbf{m})\end{array}$ & $\begin{array}{l}\text { Potência Transm. } \\
(\mathbf{W})\end{array}$ \\
\hline TIM S/A & $1,008 \mathrm{E}+09$ & 77.300 .000 .000 & 78.300 .000 .000 & 25 & 80 \\
TIM S/A & $1,008 \mathrm{E}+09$ & 77.300 .000 .000 & 78.300 .000 .000 & 25 & 80 \\
TIM S/A & $1,008 \mathrm{E}+09$ & 77.300 .000 .000 & 78.300 .000 .000 & 25 & 80 \\
\hline
\end{tabular}


Fonte: MOSAICO - Sistema Integrado de Gestão e Controle do Espectro

Todas as frequências encontradas nas redes de transmissão estão dentro da faixa de micro-ondas. Para o presente projeto foi adotado a frequência de 2,45 Ghz tendo em vista que na área de implementação do projeto existe boa quantia do sinal nesta frequência. A escolha desta faixa de frequência também propícia o aproveitamento dos sinais das redes de dados móveis citados nas tabelas acima, já que o mínimo recomendado para o comprimento do elemento radiante da antena é de $1 / 4$ do comprimento de onda e as redes de telefonia tem comprimento de onda menor, ou seja, confinam-se facilmente em estruturas condutoras maiores. Por fim foi desenvolvido em software, um arranjo com dezesseis elementos de antenas de microfita retangulares.

\subsection{SOFTWARES E PROGRAMAS UTILIZADOS}

A segunda etapa do projeto consistiu em desenvolver um código para calcular os parâmetros necessários para simulação. Foi utilizado o MATLAB para a simulação e realização dos cálculos.

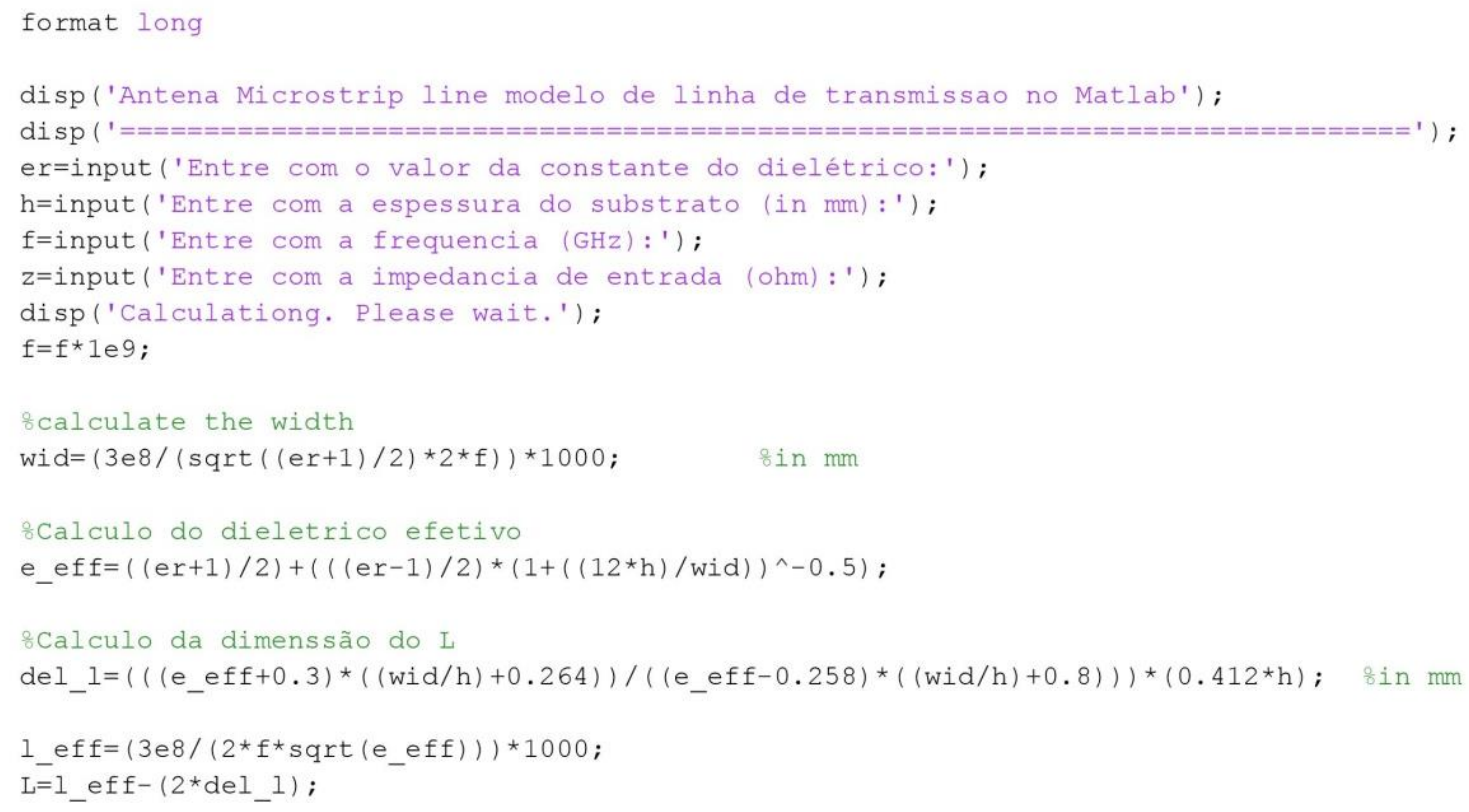




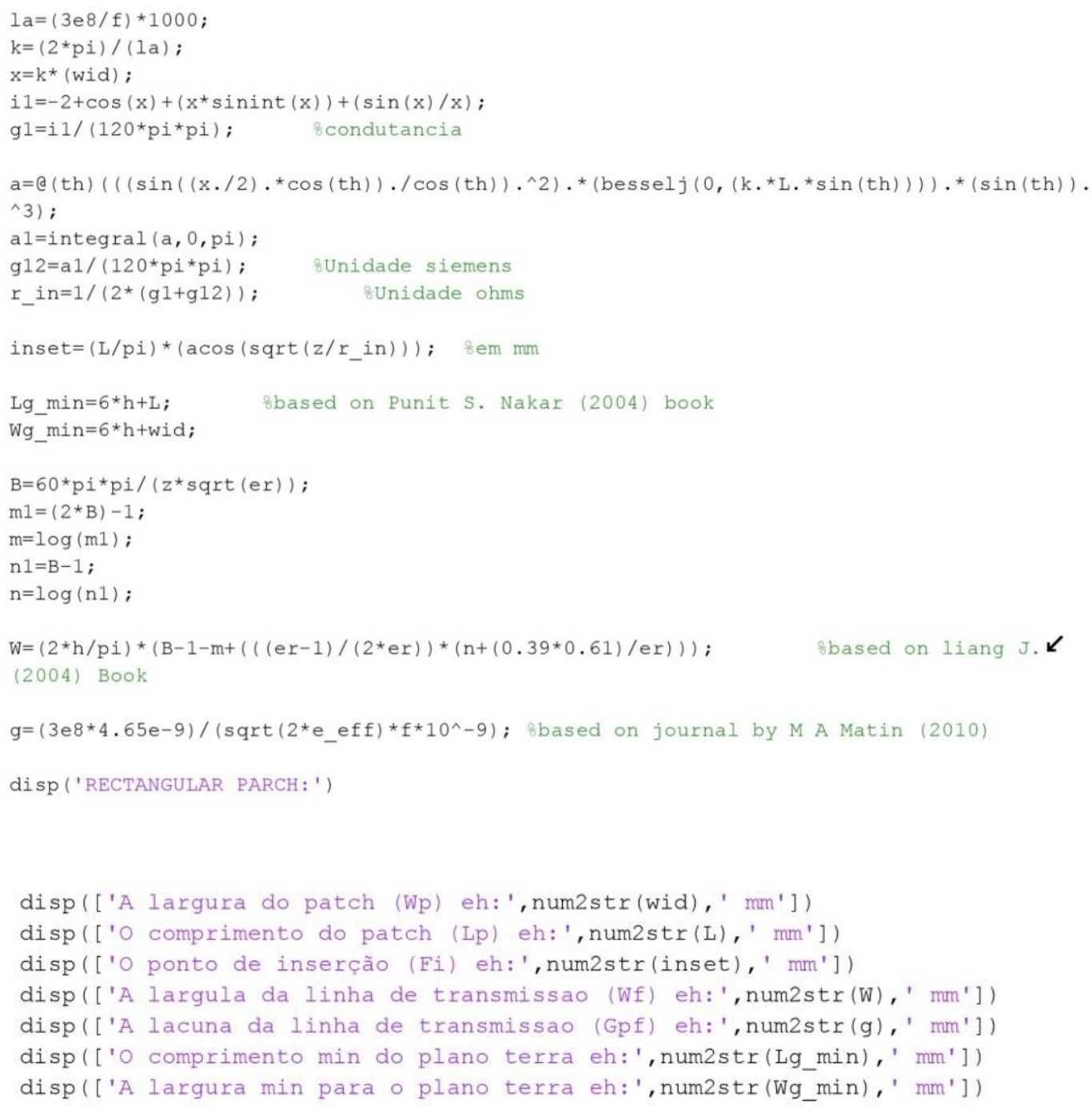

\subsection{SIMULAÇ̃̃O DO PROTÓTIPO FINAL}

Nesta seção são apresentados os resultados das simulações e esquemático do circuito dobrador de tensão que em detrimento da corrente do circuito dobra a tensão obtida fazendo uso de capacitores. Os softwares mais utilizados foram matlab, ADS, CST Studio Suite e o LTspice. Para as primeiras versões da antena foram realizadas muitas simulações em software para determinação de variáveis e parâmetros fundamentais. Tais simulações foram realizadas com parâmetros e métodos diferentes e assim obteve-se algumas versões iniciais das antenas.

Logo, para uma melhor compreensão, as simulações foram realizadas em cinco etapas, que serão descritas detalhadamente abaixo. 


\subsubsection{Desenvolvimento do primeiro elemento}

Esta etapa consiste na formulação e definição dos parâmetros imutáveis, assim como os calculados, visando descriminar primeiramente o método de excitação, dimensões do elemento radiante (patch), material dielétrico e o tipo de casamento de impedância.

O método de linha de transmissão foi escolhido como meio excitatório da antena que consiste em uma faixa estreita com dimensões específicas, feita do mesmo material do patch. Por intermédio da linha de transmissão que o elemento irradiante é excitado.

Os valores iniciais das dimensões do elemento radiante para a versões iniciais da antena, foram calculados por intermédio de um código em MatLab e métodos de convergência de valores, demonstrada através de gráficos. Em relação ao dielétrico, foi definido um material laminado -epóxi reforçado com fibra de vidro - FR4, com $1.6 \mathrm{~mm}$ de espessura e constante dielétrica de 4,6. O método de casamento de impedância adotado foi uma variação entre transformador de $1 / 4$ de onda com inset-fed e a frequência de ressonância para o projeto na faixa de micro-ondas de $2.45 \mathrm{Ghz}$.

Figura 8.1: A imagem abaixa é a execução dos calculos no programa matlab para a versão 1.1 da antena de microfita.

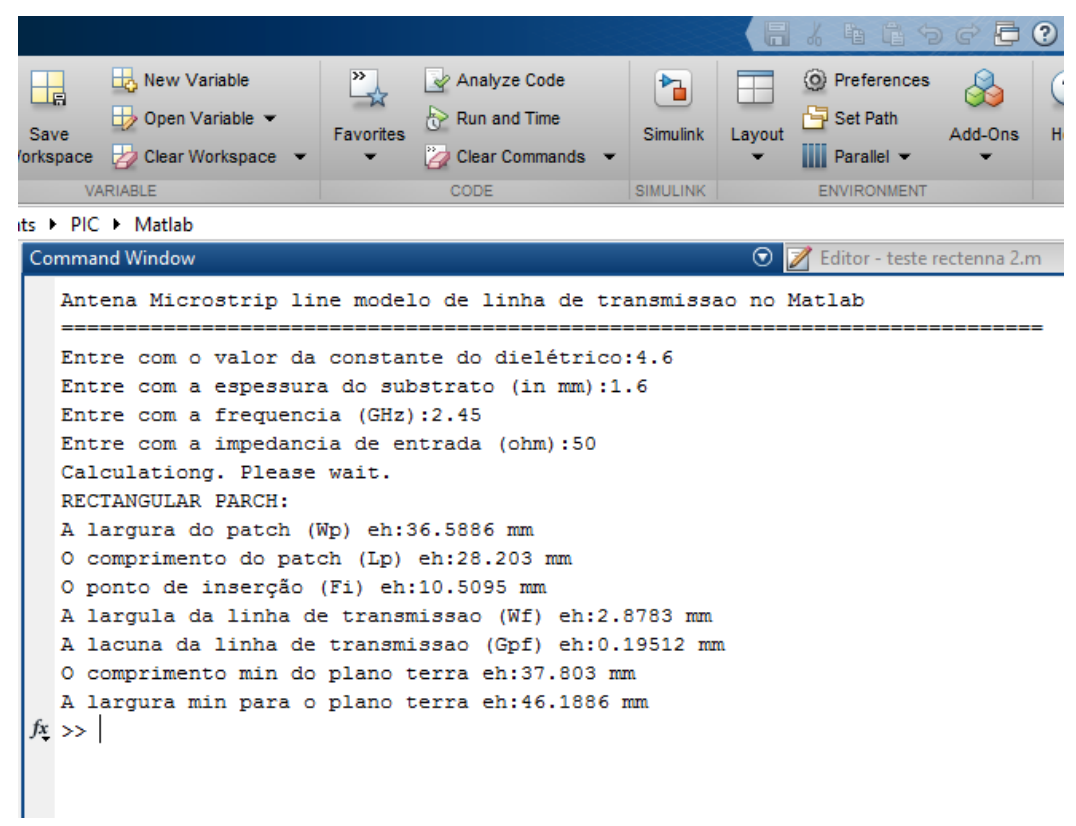

Fonte: autoria própria. 
Com base nos valores fornecidos no MatLab foi construída a estrutura teórica da antena. Os dados foram inseridos no programa ADS, em sua janela de esquematização em blocos.

Figura 8.2: Circuito esquemático em blocos e shape da versão inicial 1.1 da antena.

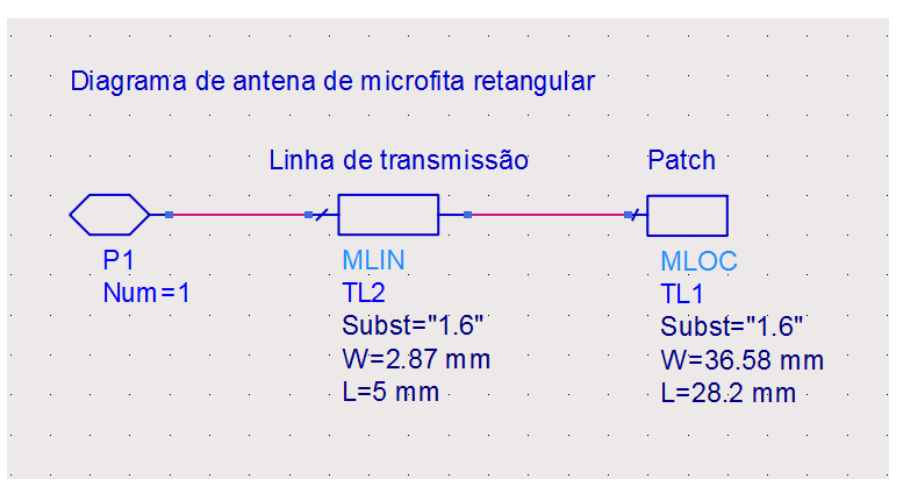

(a) Diagrama do circuito

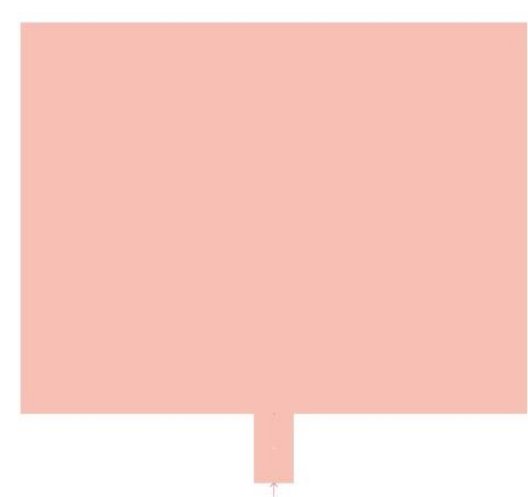

(b) Shape da antena.

Fonte: Própria.

Pode-se observar na estrutura da antena na figura 8.2 (b) onde não foram utilizados nenhum tipo de método para casamento de impedância. Os resultados das simulações mostram os gráficos a seguir.

Figura 8.3: Gráfico do coeficiente de reflexão e fase da versão inicial 1.1 da antena no ADS.

Adaptively Fitted Points

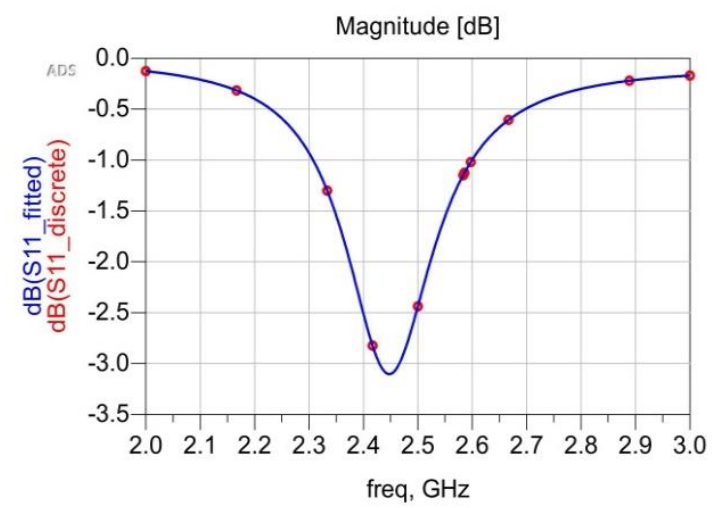

Discrete Frequency Points

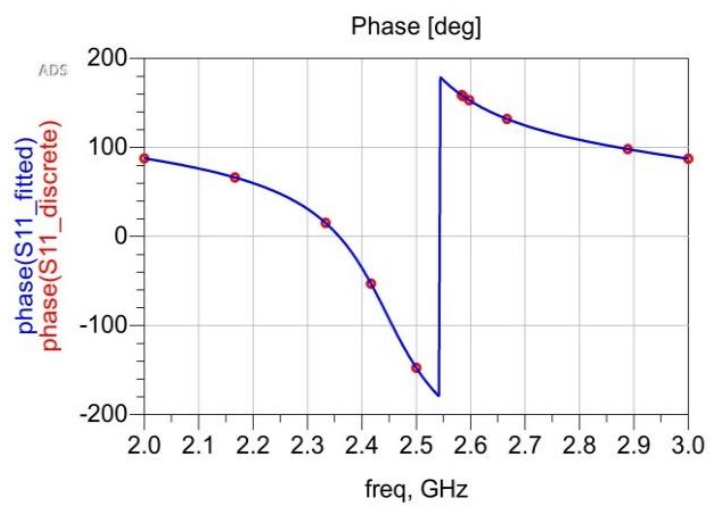

Fonte: Própria. 
Figura 8.4: Parâmetros fundamentais da antena inicial versão 1.1: Ganho, diretividade, eficiência e energia irradiada.
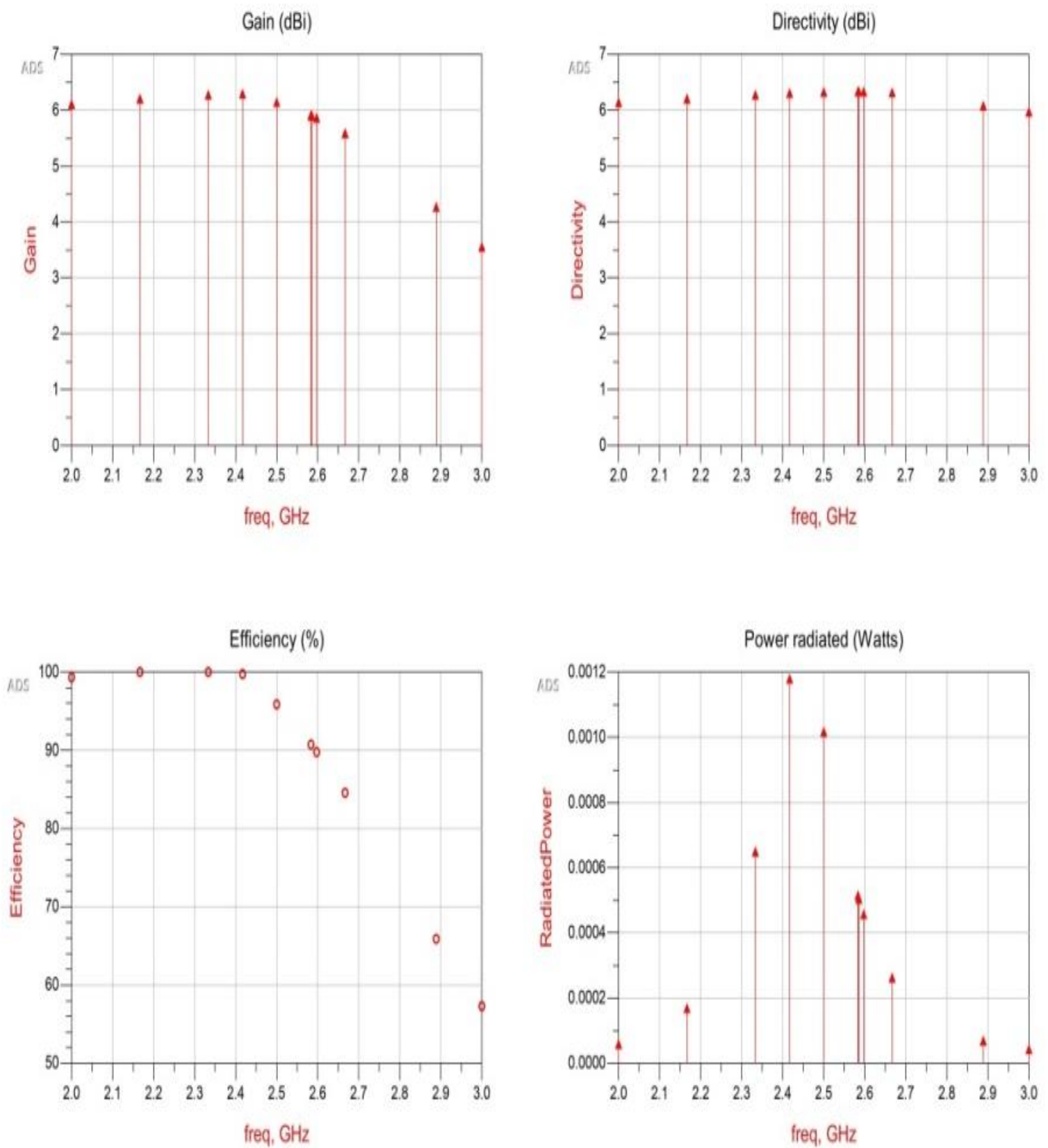

Fonte: Própria. 
Figura 8.5: Carta de Smith versão inicial 1.1 da antena.

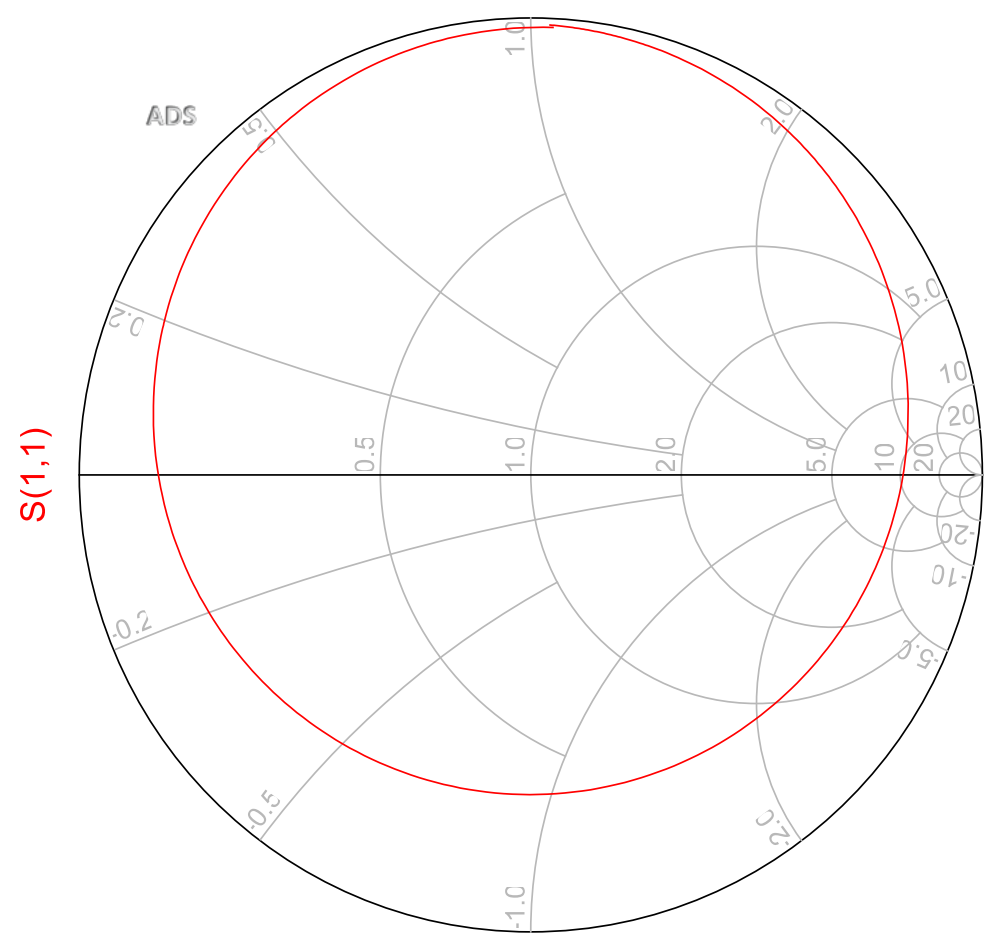

freq $(2.000 \mathrm{GHz}$ to $3.000 \mathrm{GHz})$

Fonte: Própria.

Para a versão inicial 1.2, utilizou-se valores encontrados nas literaturas para inicializar as simulações. Utilizando o software ADS, foi possível visualizar graficamente a convergência dos parâmetros até um resultado satisfatório.

Figura 8.6: Circuito esquemático em blocos e shape da versão inicial 1.2 da antena.

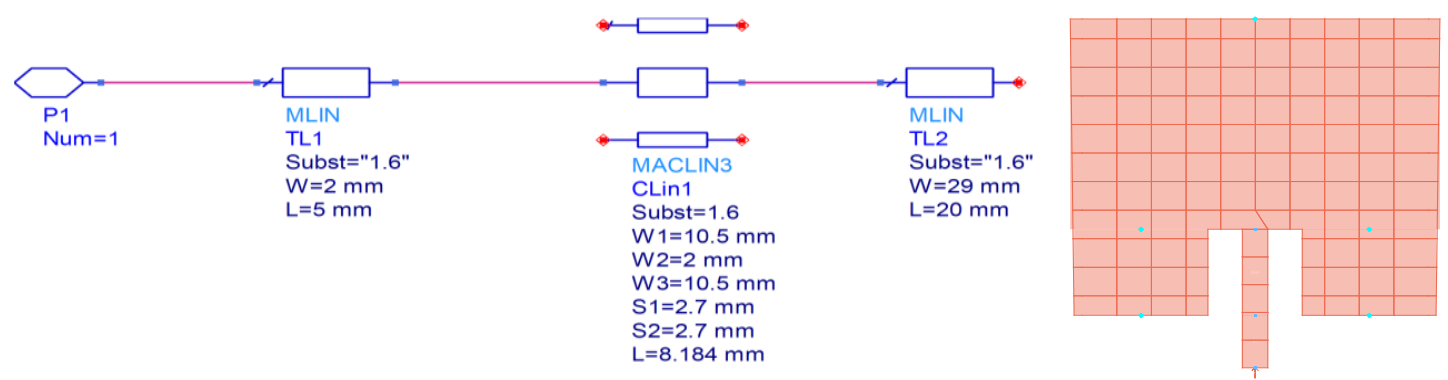

$\begin{array}{ll}\text { a) Diagrama do circuito } & \text { (b) Shape da antena. }\end{array}$

Fonte: Própria. 
Figura 8.7: Gráfico do coeficiente de reflexão e fase da versão inicial 1.2 da antena no ADS.

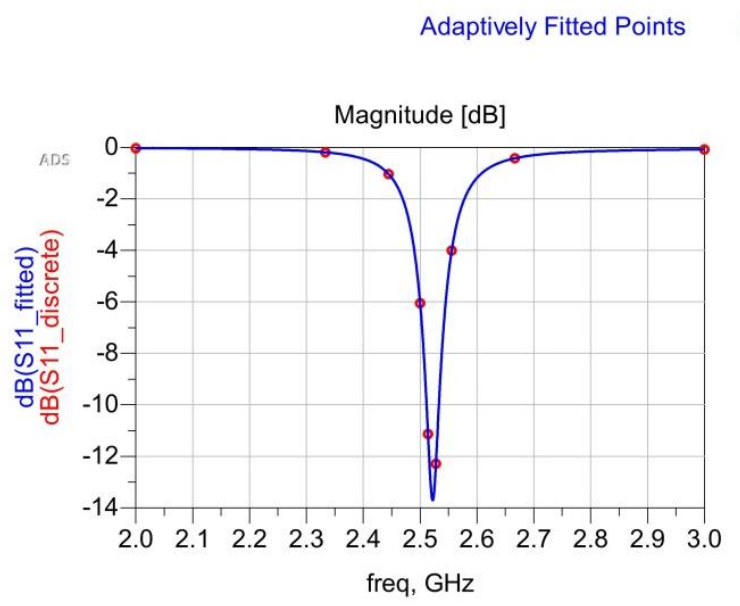

Discrete Frequency Points

Fonte: Própria.

Figura 8.8: Parâmetros fundamentais da antena inicial versão 1.2 sem ajuste: Ganho, diretividade, eficiência e energia radiada.
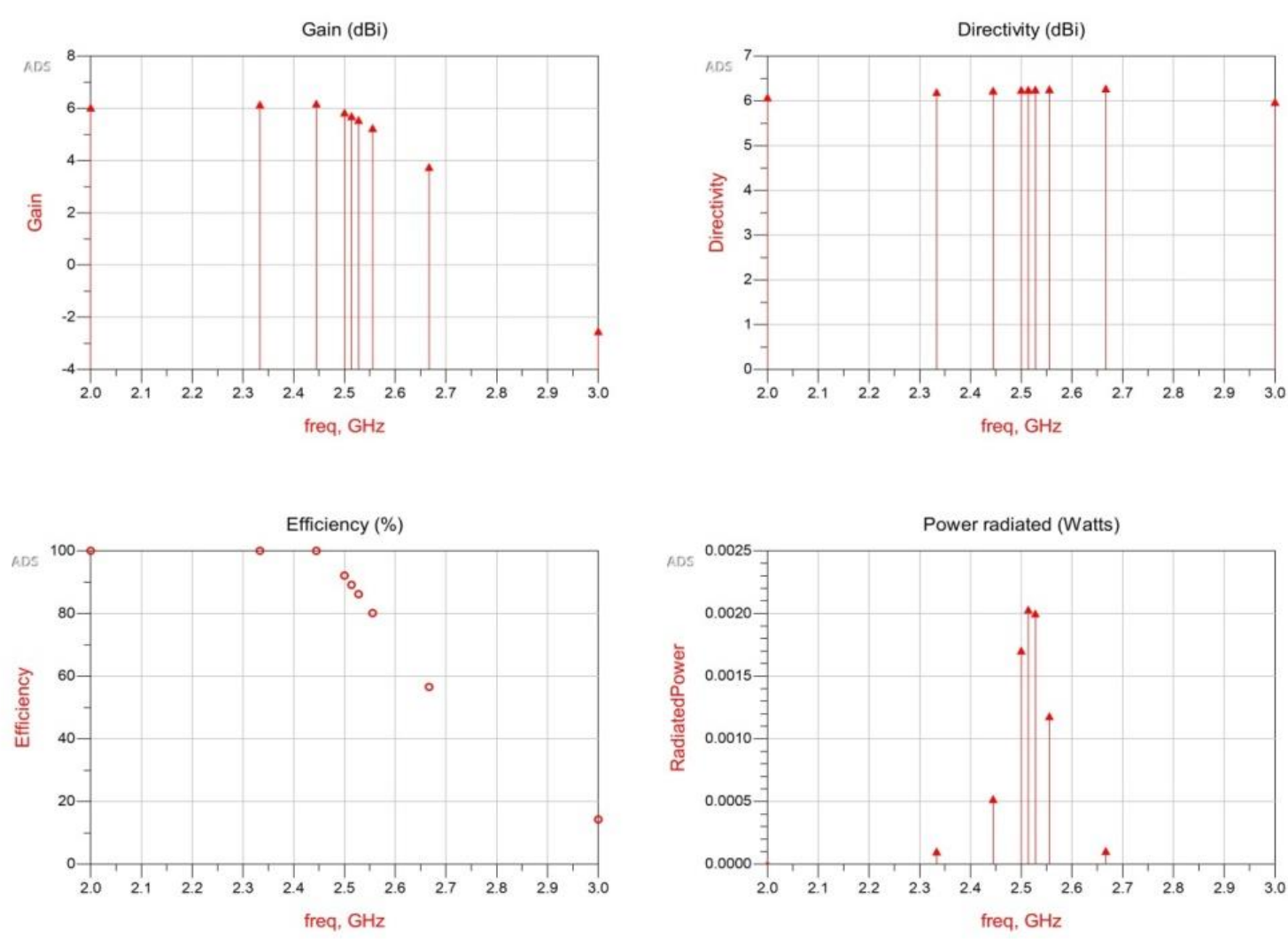

Fonte: Própria. 
Figura 8.9: Gráfico da convergência do parâmetro cavidade para ajustar o casamento de impedância da versão inicial 1.2.
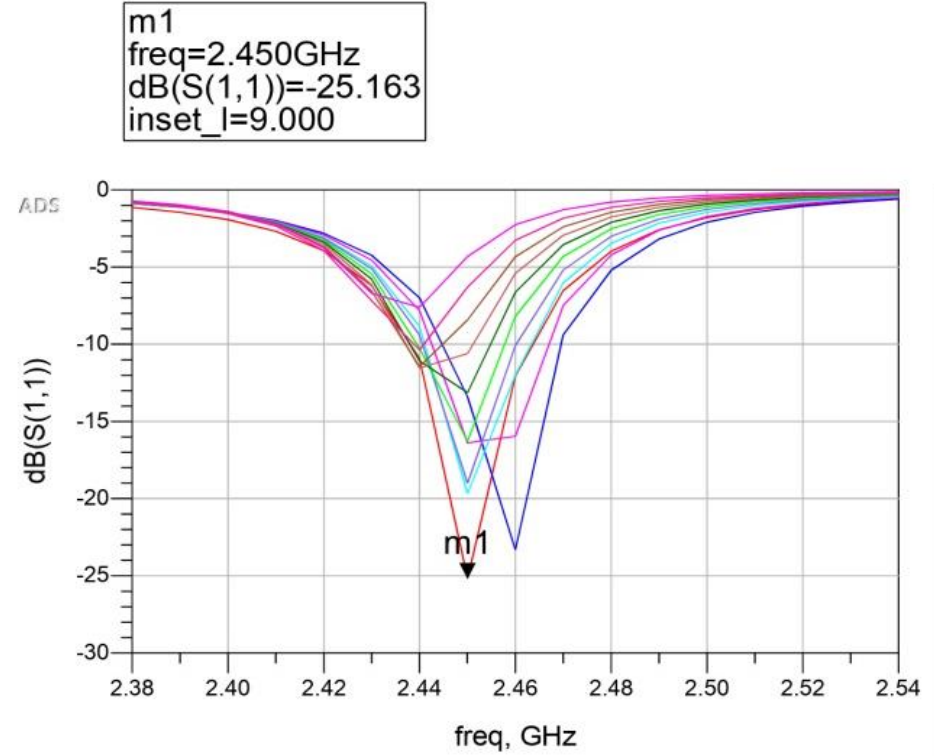

Fonte: Própria.

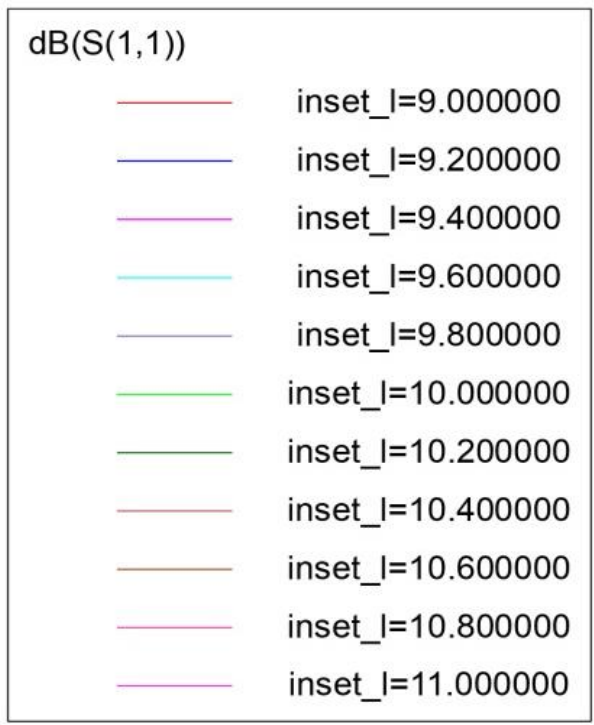

Nota-se que na cor vermelho com inset de $9 \mathrm{~mm}$, se tem a maior convergência, na azul com inset de 9,2 mm começa a divergir, mas em ambos casos a magnitude é maior, evidenciado menores coeficientes de reflexão. Contudo, a curva em vermelho mostra maior sintonia com a frequência especificada de $2,45 \mathrm{GHz}$ mostrando maior eficiência.

Figura 8.10: Gráfico da convergência do parâmetro $L$ para ajustar a ressonância em 2.45 Ghz da versão inicial 1.2.

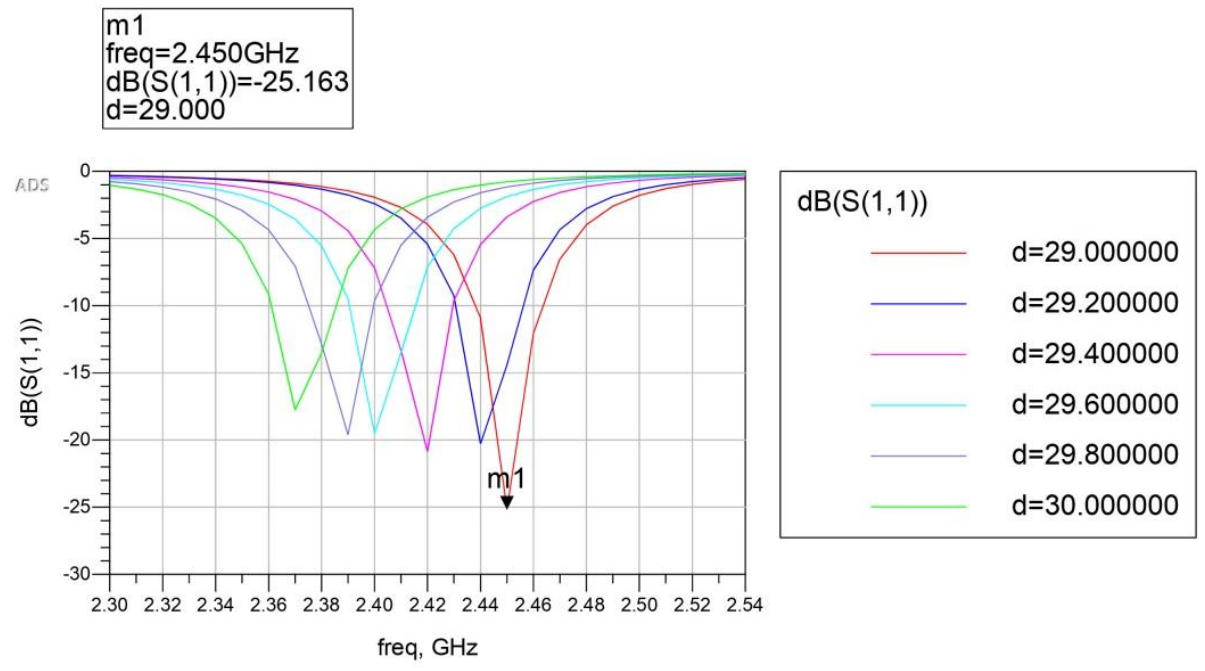

Fonte: Própria. 
Figura 8.11: Esquemático da simulação para ajustar os parâmetros da versão inicial 1.2.

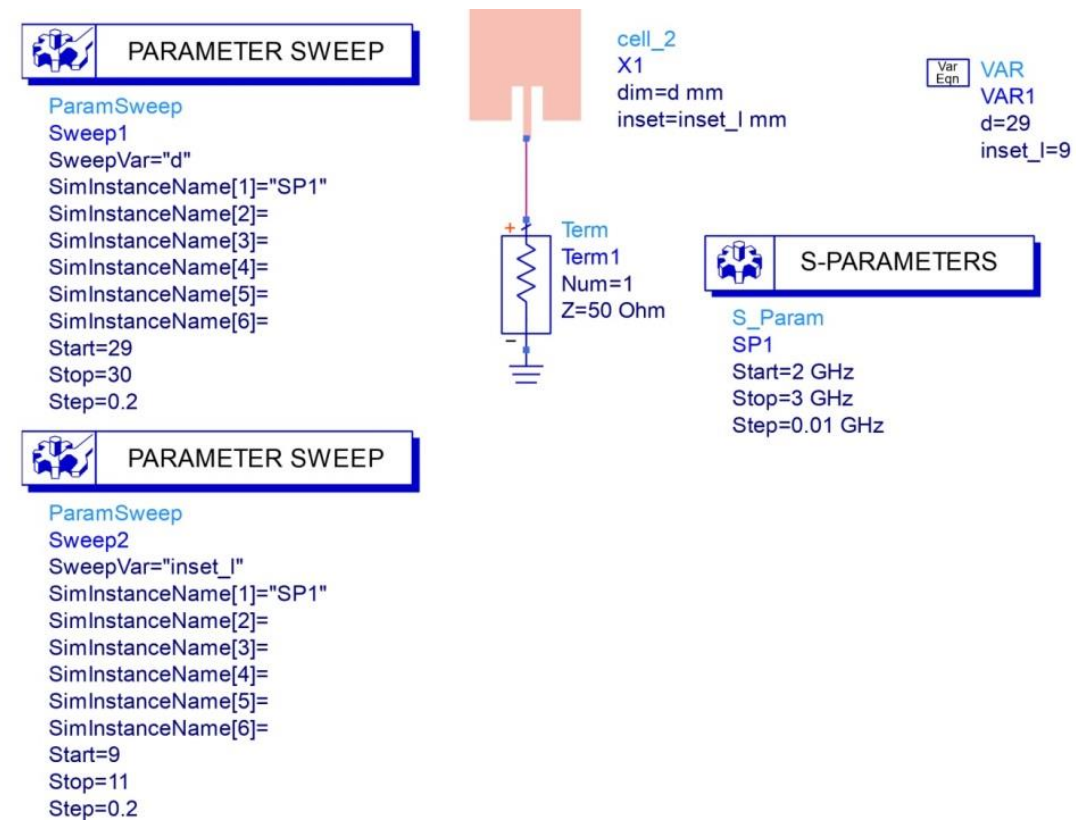

Fonte: Própria.

Figura 8.12: Gráfico do coeficiente de reflexão e fase da versão inicial 1.2 ajustada no ADS.

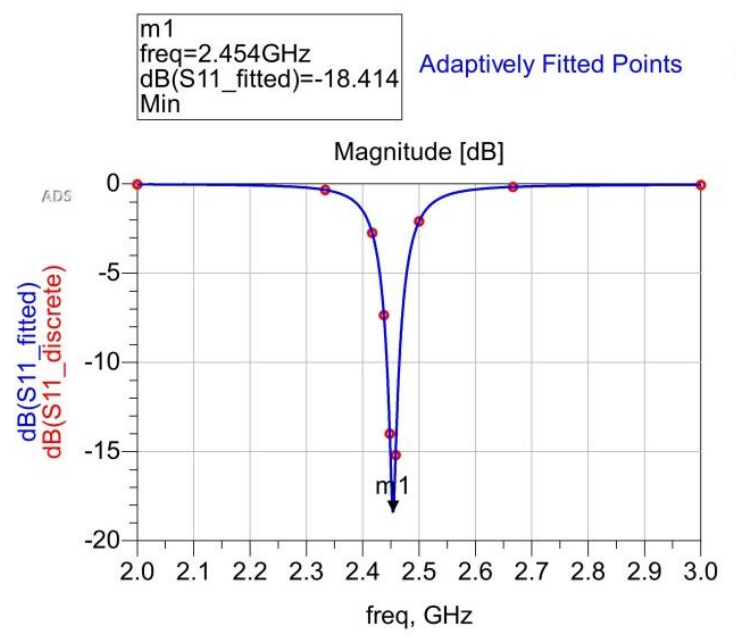

Discrete Frequency Points

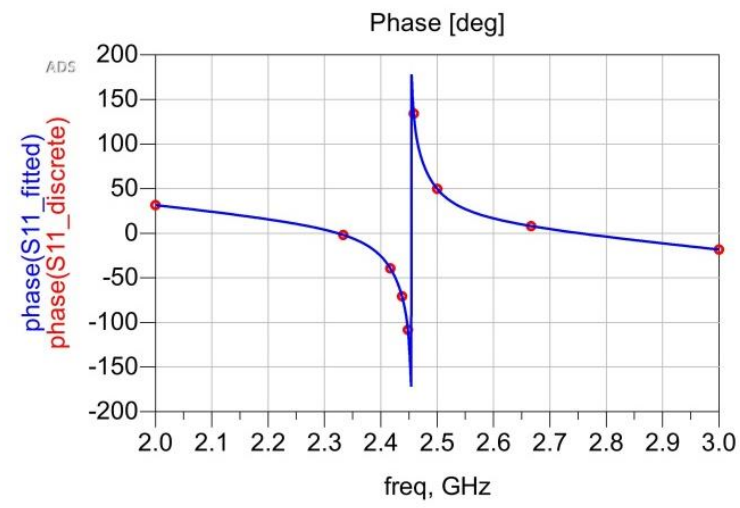

Fonte: Próprio. 
Figura 8.13: Parâmetros fundamentais da antena inicial versão 1.2 com ajuste: Ganho, diretividade, eficiência e energia radiada.
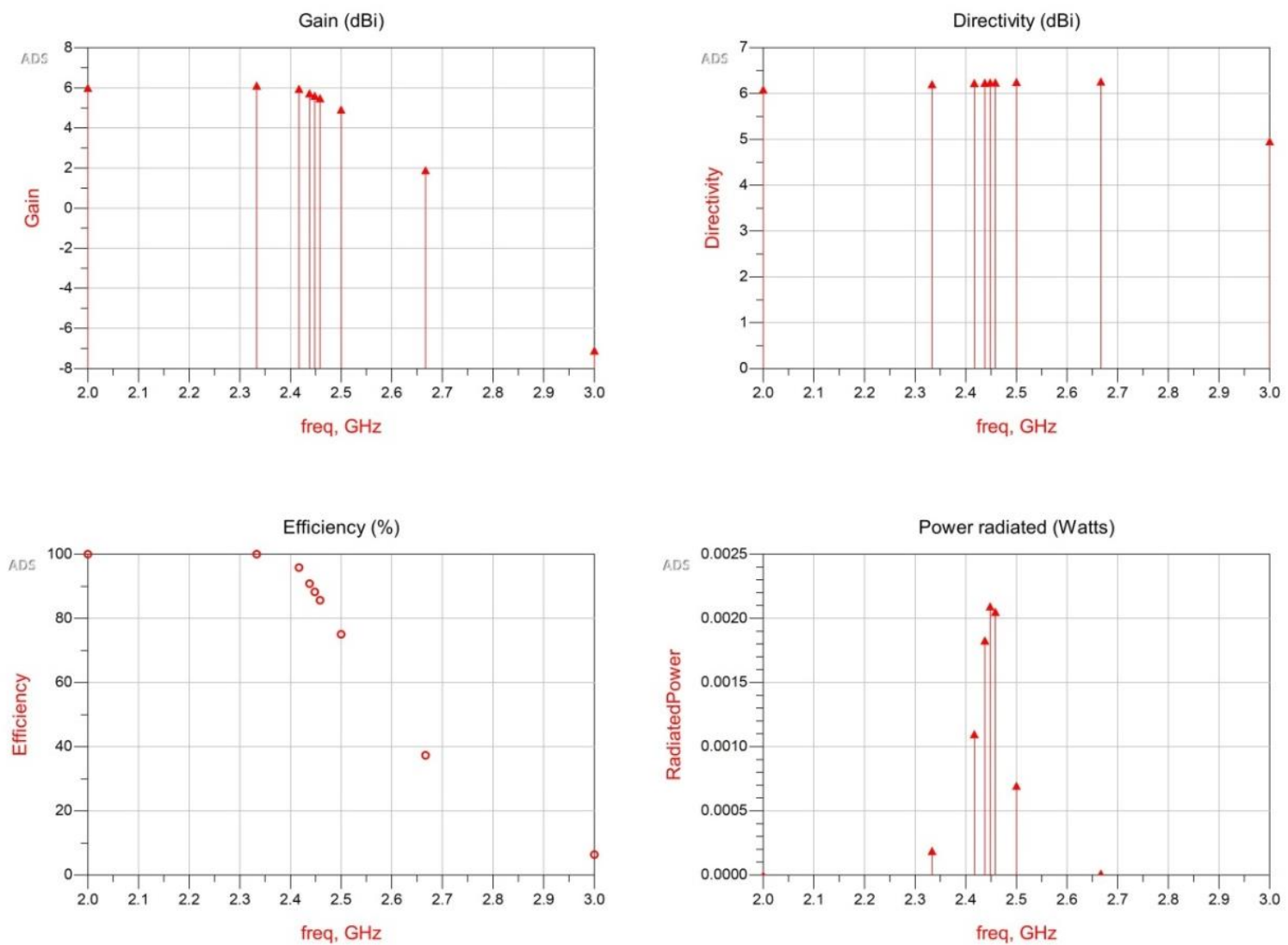

Fonte: Própria.

A versão inicial 1.2 foi selecionada para a segunda fase do projeto que consiste no desenvolvimento dos arranjos de antenas de microfita. As simulações foram executadas em três etapas, sendo que a primeira efetuada com um arranjo de dois elementos, a segunda etapa foi com a disposição de quatro elementos e por fim foi simulado um arranjo com dezesseis elementos de antenas.

Posteriormente, serão expostos os resultados dos parâmetros fundamentais das antenas simuladas em uma tabela para comparação dos dispositivos. Entretanto, para apresentação por etapas só ocorrerá da versão inicial 1.2. 


\subsubsection{Arranjo de dois elementos}

As antenas foram transformadas em blocos e interligadas com conexãos de diversos dimensoes. As distancias foram simuladas para atingir o melhor acoplamento entre cada elemento radiante com base nas literatura.

Figura 8.14: Diagrama de arranjo de dois elementos da antenas inicial 1.2.

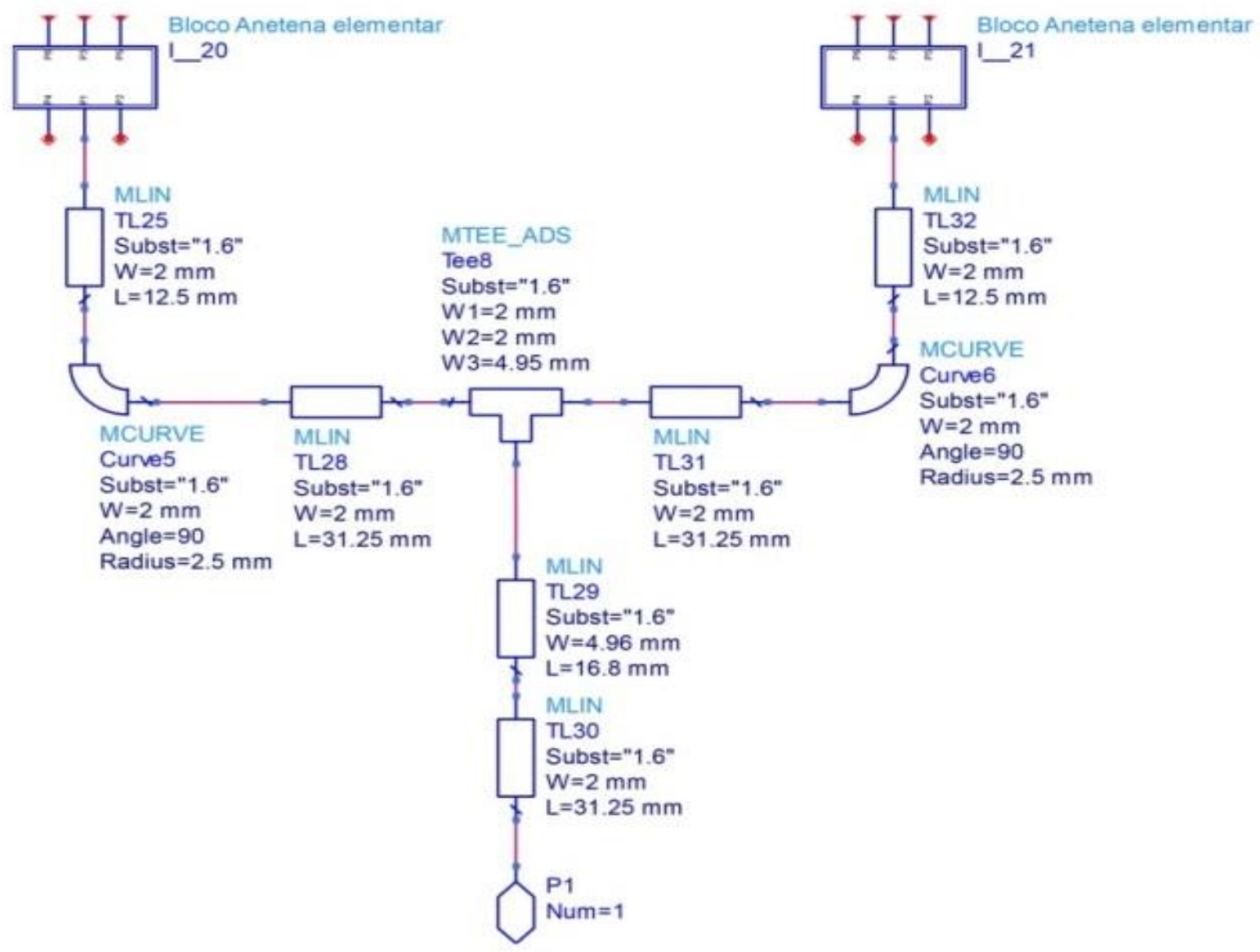

Fonte: Próprio.

As simulações dos parâmetros fundamentais da antena, tais como: ganho, diretividade, eficiência e potência irradiada estão apresentados na figura 8.15 , em forma de gráficos. Todos os parâmetros estão em função da frequência de ressonância do sistema de $2.45 \mathrm{GHz}$. 
Figura 8.15:. Parâmetros fundamentais do arranjo de dois elementos: Ganho, diretividade, eficiência e potência irradiada.
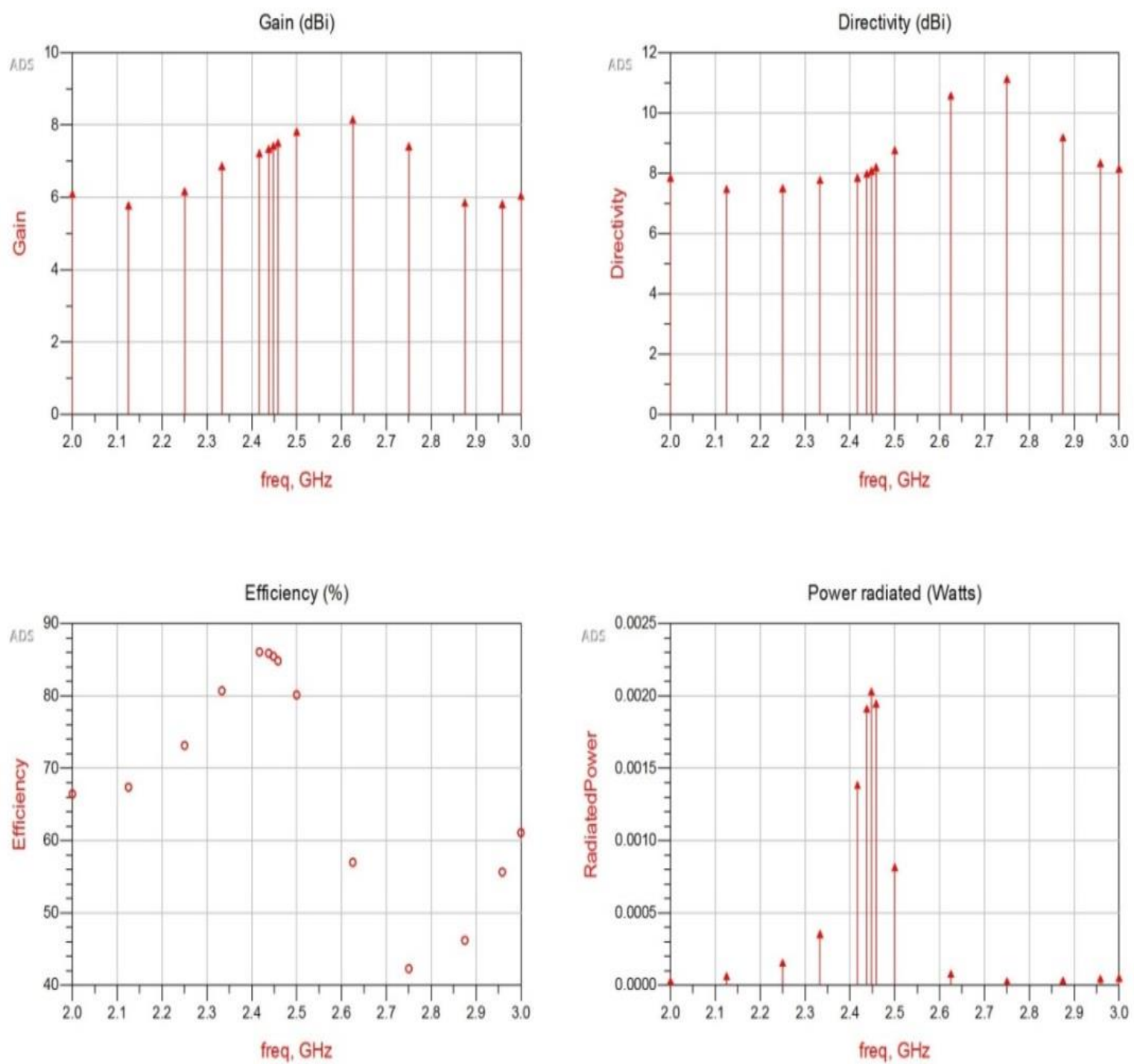

Fonte: Própria.

\subsubsection{Arranjo de quatro elementos}

Figura 8.16: Carta de Smith de arranjo de quatro elementos. 

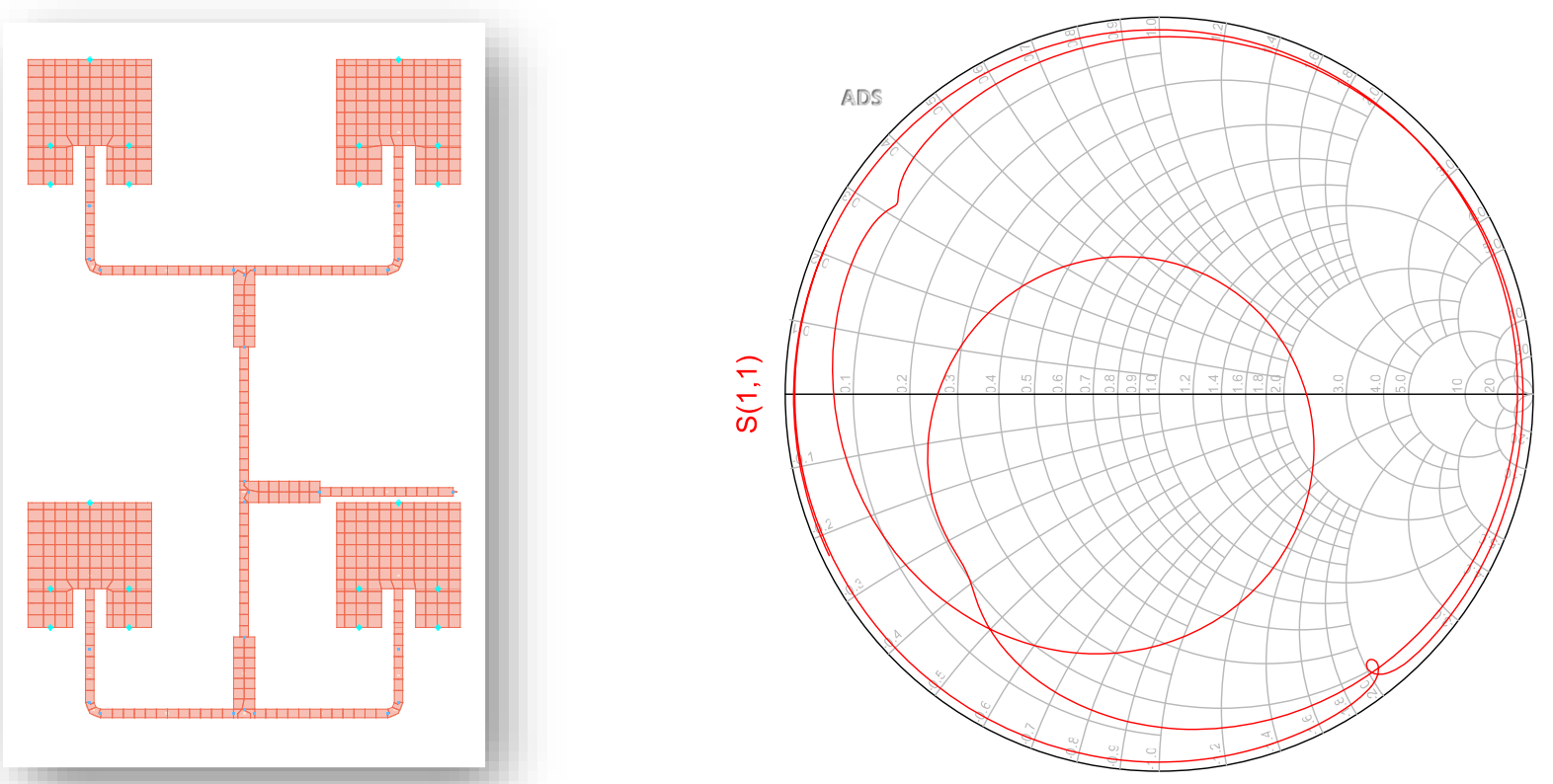

freq $(2.000 \mathrm{GHz}$ to $3.000 \mathrm{GHz})$

\section{Fonte: Própria.}

Figura 8.17: Gráfico do coeficiente de reflexão e fase do arranjo de quatro elementos no ADS.
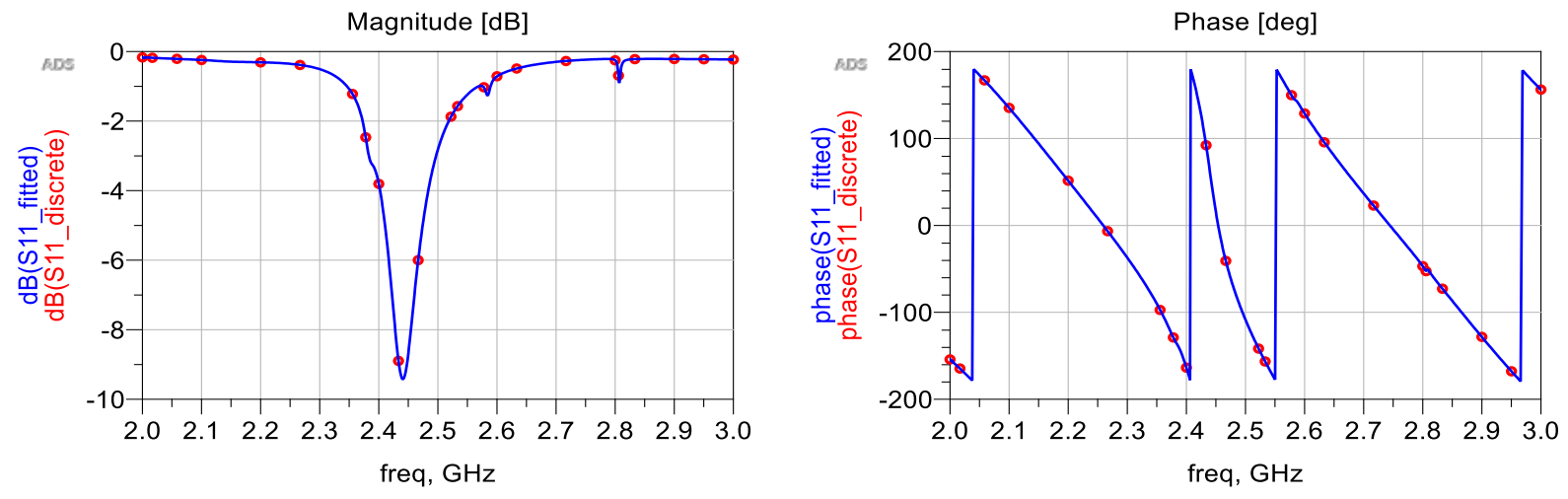

\section{Fonte: Própria.}




\subsubsection{Arranjo completo com 16 elementos}

As simulações dos parâmetros fundamentais da antena tais como ganho, diretividade, eficiência e potência irradiada estão apresentados na figura 8.18 em forma de gráficos. Todos os parâmetros estão em função da frequência de ressonância do sistema de $2.45 \mathrm{GHz}$.

Figura 8.18: Parâmetros fundamentais do arranjo completo com dezesseis elementos utilizando versão inicial 1.1: Ganho, Diretividade, Eficiência e potência radiada.

\section{Antenna Parameters vs Frequency}
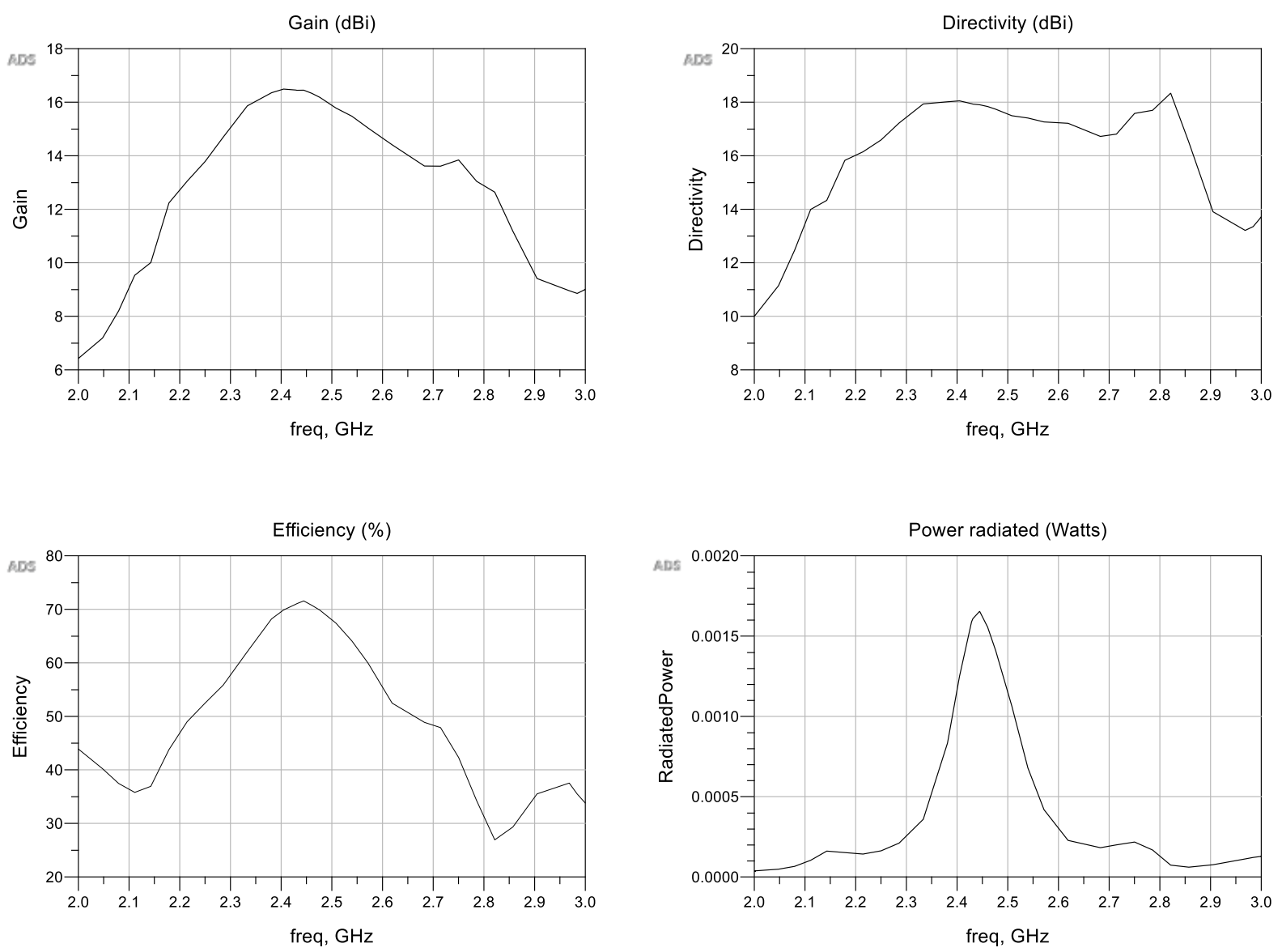

Fonte: Própria.

A proposta deste gráfico da versão inicial 1.1 e para comparação final com o arranjo de dezesseis elementos da versão 1.2.

Pode-se verificar uma pequena diferença nos parâmetros fundamentais, principalmente em relação a eficiência, entretanto os valores não assumem divergências 
discrepantes. Contudo como já relatado, tanto a versão 1.1 quanto a versão 1.2 tem desempenhos similares no quesito de arranjo.

Figura 8.19: Imagem do designer do arranjo de dezesseis elementos utilizando a versão inicial 1.2 no ADS.

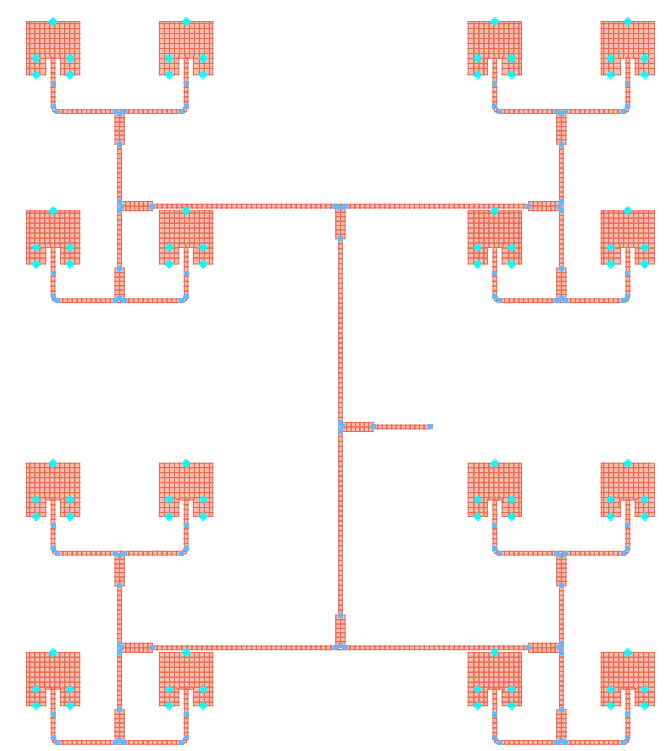

Fonte: Própria.

Figura 8.20: Gráfico do coeficiente de reflexão e fase do arranjo de dezesseis elementos da antenas inicial 1.2 no ADS.

Adaptively Fitted Points

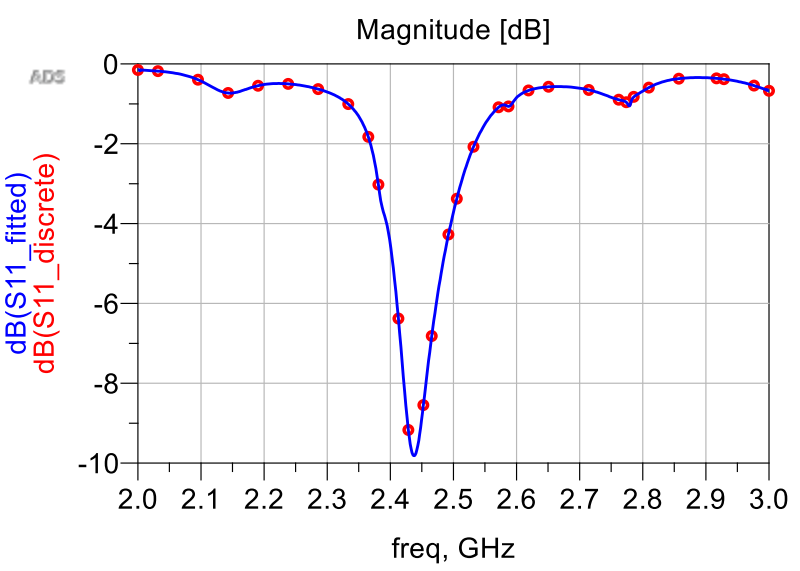

Discrete Frequency Points

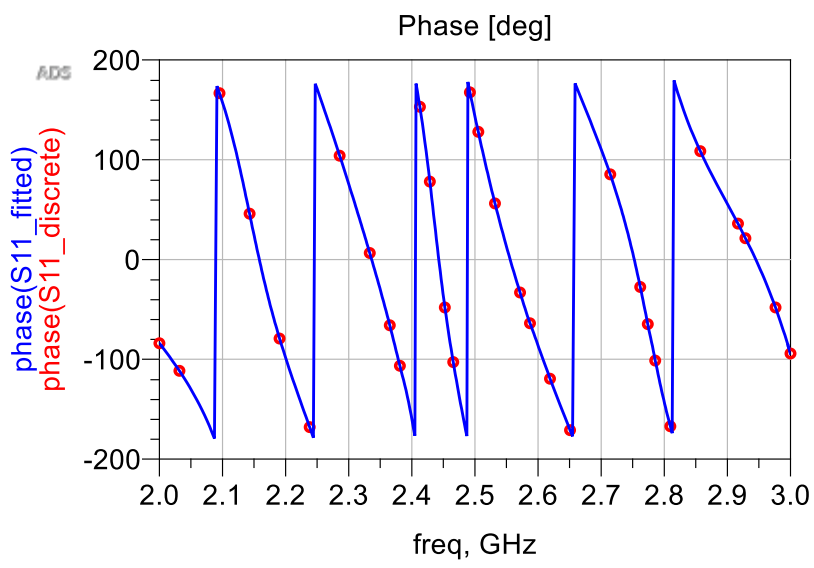

Fonte: Própria. 
Incrementar comentários e análise em relação ao anterior. Convém entrar no ADS e ver como ele expõe os parâmetros do gráfico para que você siga linha similar na explicação

Figura 8.21: Carta de Smith do arranjo de dezesseis elementos.

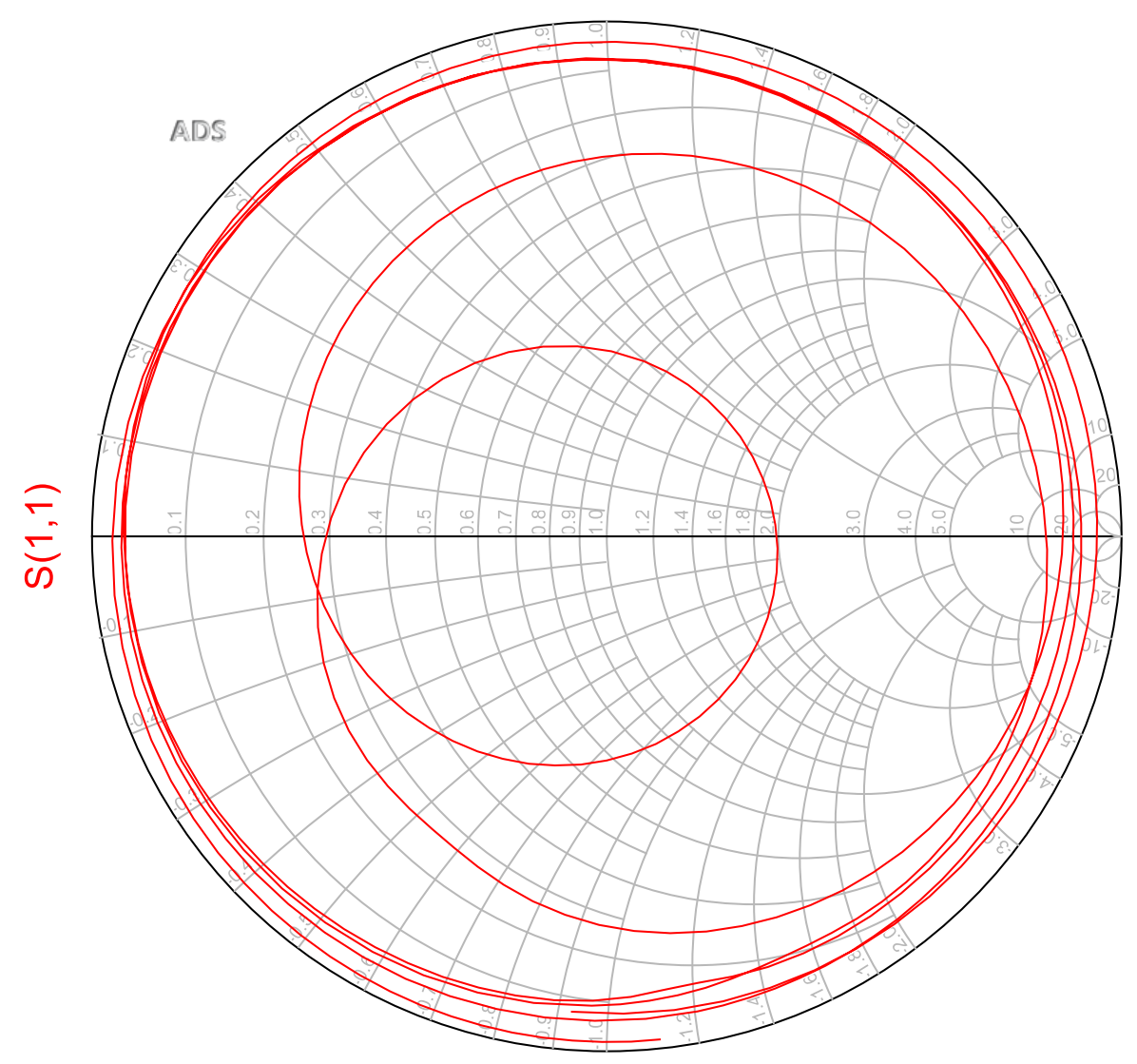

freq $(2.000 \mathrm{GHz}$ to $3.000 \mathrm{GHz})$

Fonte: Própria.

Nota-se que quanto maior o círculo maior a eficiência na potência irradiada com menor coeficiente de reflexão (ver carta de Smith).

As simulações dos parâmetros fundamentais do arranjo de dezesseis elementos de antenas de microfita, tais como ganho, diretividade, eficiência e potência irradiada estão apresentados na figura 8.22 em forma de gráficos. Todos os parâmetros estão em função da frequência de ressonância do sistema de $2.45 \mathrm{GHz}$. 
Figura 8.22: Parâmetros fundamentais do arranjo de dezesseis elementos utilizando a verão inicial 1.2: Ganho, Diretividade, Eficiência e potência radiada.
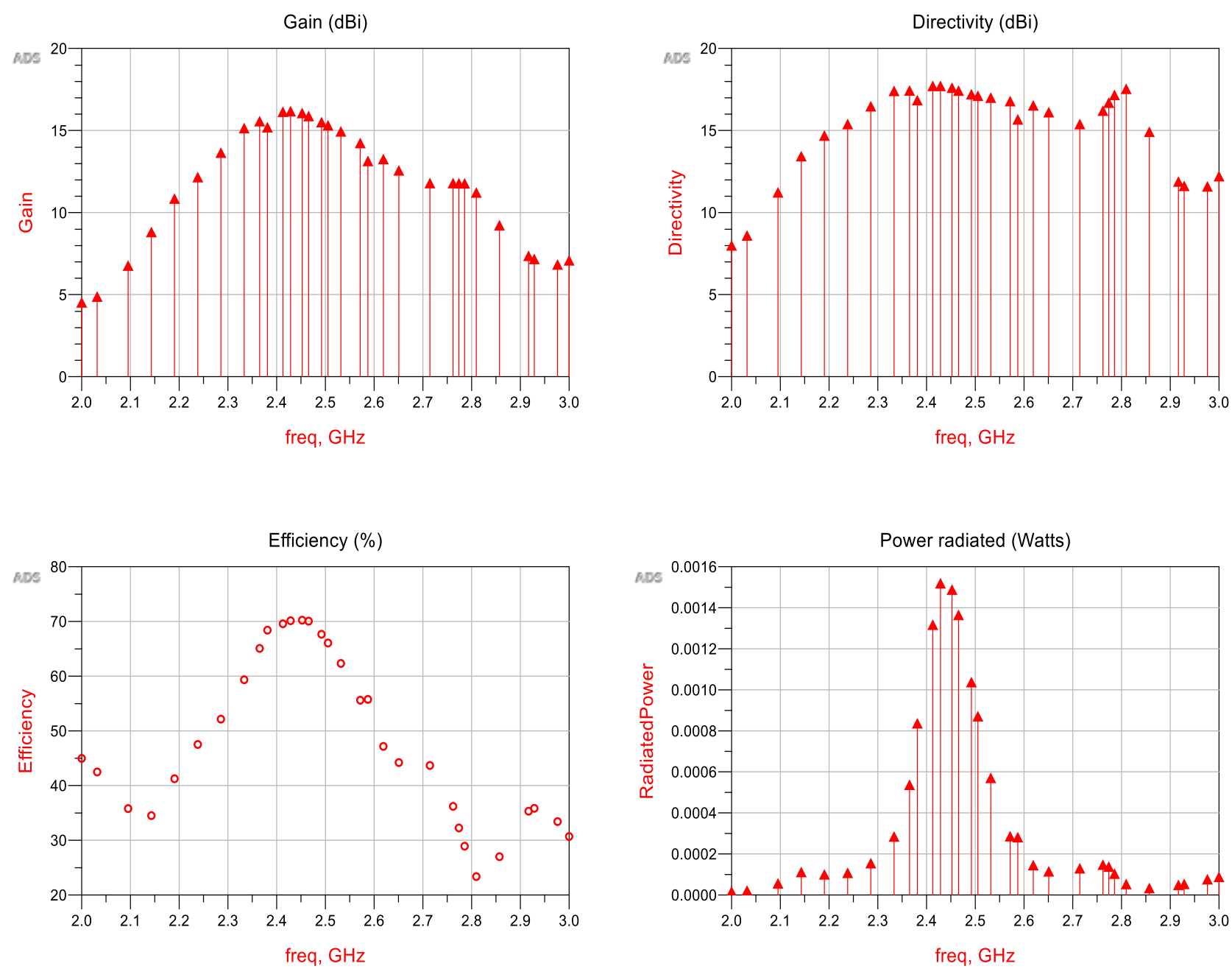

Fonte: Própria

Por fim, concluindo a etapa de arranjos a figura 8.22 apresenta os resultados das simulações dos parâmetros fundamentais do arranjo de dezesseis elementos utilizando a versão inicial 1.2.

Esta antena possui uma maior concentração de radiação na frequência de 2,45 Ghz devido um melhor casamento de impedância com a linha de transmissão. A eficiência do arranjo é aproximadamente 70,21 \% não obstante dos 71,57\% da versão 1.1. Contudo como mencionando anteriormente versão inicial 1.2 possui dimensões favoráveis para implementação pratica não industrial. 


\section{CIRCUITO RETIFICADOR E DOBRADOR DE TENSÃO}

Figura 9.1: Diagrama demonstrativo dos circuitos retificador e dobrador de tensão montado no ADS.

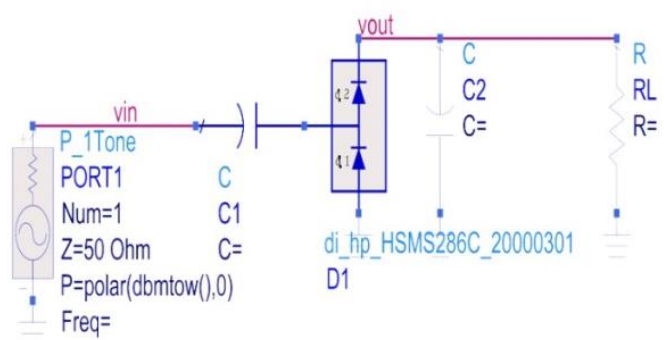

a) Retificador de meia onda

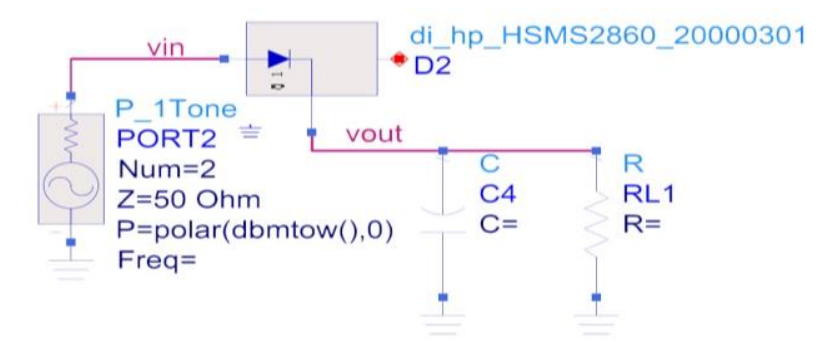

b) Dobrador de tensão Villard.

Fonte: Própria.

Os circuitos de retificação e dobrador de tensão Villard, funcionam bem individualmente, entretanto para a conexão com o arranjo da antena faz-se necessário um casamento de impedância mais detalhado.

\section{RESULTADOS E DISCUSSÃO}

A versão inicial 1.1 apresentou melhor desempenho no quesito individual e em conjunto, mesmo que tenha deixado a desejar no item de frequência de ressonância. Entretanto o seu corte para casamento de impedância torna-se inviável devido dificuldades de fabricação artesanal por ser muito estreito. Contudo ao compararmos ambas versões iniciais verificou-se que seus parâmetros estão dentro de uma faixa satisfatória para o projeto e assim optamos pela versão inicial 1.2. Em relação aos arranjos a tabela 6 demostra o comportamento dos parâmetros fundamentais ao associar diversos elementos onde pode-se observar a evolução do ganho e diretividade em detrimento da eficiência.

Os níveis de maior eficiência são de elementos individuais contidos nas versões inicias 1.1 e 1.2 entretanto constatamos que com a associação das antenas a eficiência tem reduzido, porém com a sobreposição de diversos sinais e com o aumento dos paramentos ganho e diretividade a perda de eficiência nos arranjos tornam-se compensatórias. 
Tabela 6 - Comparativos dos parâmetros fundamentais das antenas simuladas

\begin{tabular}{|c|c|c|c|c|c|c|}
\hline & Ganho & Diretividade & Eficiência & PR [W] & TS & FR \\
\hline VERSÃO 1.1 & 6,37026 & 6,38079 & $99,76 \%$ & 0,001192 & $6 \mathrm{~s}$ & $2,4166 \mathrm{GHZ}$ \\
\hline VERSÃO 1.1 COM CORTE & 5,82115 & 6,403 & $87,46 \%$ & 0,0021607 & $7 \mathrm{~s}$ & $2,458 \mathrm{GHZ}$ \\
\hline VERSÃO 1.2 & 5,64069 & 6,31349 & $85,65 \%$ & 0,0020765 & $9 \mathrm{~s}$ & $2,458 \mathrm{GHZ}$ \\
\hline $\begin{array}{l}\text { ARRANJO DE } 2 \\
\text { ELEMENTOS; VESÃO } 1.1\end{array}$ & 8,00112 & 8,54801 & $86,28 \%$ & 0,001098 & $15 \mathrm{~s}$ & 2,4335 GHZ \\
\hline $\begin{array}{l}\text { ARRANJO DE } 2 \\
\text { ELEMENTOS; VESÃO } 1.2\end{array}$ & 7,60167 & 8,31605 & $84,83 \%$ & 0,0019713 & $13 \mathrm{~s}$ & $2,45833 \mathrm{GHZ}$ \\
\hline $\begin{array}{l}\text { ARRANJO DE QUATRO } \\
\text { ELEMENTOS; VERSÃO } 1.1\end{array}$ & 10,8962 & 11,9935 & $77,67 \%$ & 0,0015507 & $33 \mathrm{~s}$ & $2,467 \mathrm{GHZ}$ \\
\hline $\begin{array}{l}\text { ARRANJO DE QUATRO } \\
\text { ELEMENTOS; VERSÃO } 1.2\end{array}$ & 10,8624 & 11,9946 & $77,05 \%$ & 0,001683 & $44 \mathrm{~s}$ & $2,45 \mathrm{GHZ}$ \\
\hline $\begin{array}{l}\text { ARRANJO DE } 16 \\
\text { ELEMENTOS; VERSÃO } 1.1\end{array}$ & 16,4487 & 17,9011 & $71,57 \%$ & 0,0016539 & $7 \mathrm{~min}$ & 2,444 Ghz \\
\hline $\begin{array}{l}\text { ARRANJO DE } 16 \\
\text { ELEMENTOS; VERSÃO } 1.2\end{array}$ & 16,3324 & 17,8684 & $70,21 \%$ & 0,00151 & $5 \mathrm{~min}$ & $2,4523 \mathrm{GHz}$ \\
\hline
\end{tabular}

TS - Tempo de simulação; FR - Frequência de ressonância; PR - Potência radiada

Fonte: Própria.

\section{CONSIDERAÇÕES FINAIS}

A antena projetada apresenta excelentes resultados com uma ótima eficiência e ganho sendo satisfatório para a implementação pratica. Os arranjos foram bem otimizados assim como os guias de ondas que resultou em uma antena simples robusta e com pequenas dimensões.

O sistema apresentou falhas no casamento dos circuitos de retificação e dobrador de tensão inviabilizando a simulação dos elementos em conjunto. Para trabalhos futuros pretende-se elaborar o casamento dos circuitos citados em conjunto com o arranjo das antenas. Tendo em vista que o estudante já estará mais familiarizado com o assunto, e os materiais necessários já estarão disponíveis para um maior aprofundamento do tema. 


\section{REFERÊNCIAS}

1. Leite RB, Bulcão MP. Os efeitos da radiação eletromagnética na vida do ser humano : uma análise do paradigma ambiental. Revista tecnologia e Sociedade [Internet]. 2007;3 (5):15-31. Disponível em: http://www.redalyc.org/articulo.oa?id=496650324002.

2. Farias LM, Sellitto MA. Uso da energia ao longo da história: evolução e perspectivas futuras. Revista Liberato, Novo Hamburgo [online]. Jan./jun2011. v. 12, n. 17, p. 01106. Disponível em:

http://www.liberato.com.br/sites/default/files/arquivos/revista_sier/v.\%2012,\%20n.\%2 017\%20(2011)/1.\%20uso\%20da\%20energia\%20ao\%20longo\%20da\%20hist\%f3ria.pd f.

3. Brasil. Engenharia empreendedorismo. Brasília-DF: faculdade de tecnologia. Centro Universitário de Brasília; 2019.

4. Anais 7. Simpósio internacional de educação e comunicação; 14-16 set 2016; Aracaju (SE): Universidade Tiradentes; 2016.

5. Noble D, et al. Introdução aos sistemas de comunicação sem fio. Theodore S. Rappaport. Comunicações sem fio: princípios e práticas. São Paulo: Pearson prentice hall; 2009. P. 1-16.

6. Rappaport. Theodore S. Comunicações sem fio: Princípios e praticas. 2.ed. São Paulo: Pearson- Prentece Hall, 2008. Capítulo 2, Sistemas modernos de comunicação sem fio; p. 28 29.

7. Center for software defined radio. Software defined radio: terms, trends and perspectives: Aalborg Universitet. 2007.

8. BBC News. A radiação da tecnologia 5G faz mal à saúde? [publicação online]; 2019 [acesso em 15 jul 2019]. Ciência e tecnologia. Disponível em:

https://www.bbc.com/portuguese/geral-48987729.

9. Brasil. Lei n. 9.605 de 12 de fevereiro de 1998. Dispõe sobre as sanções penais e administrativas derivadas de condutas e atividades lesivas ao meio ambiente e dá outras providências. Diário Oficial da União. 12 fev 1998. Disponível em: http://www.planalto.gov.br/ccivil_03/leis/19605.htm.

10. Ministério da Saúde. Radiação não-ionizante. [publicação online]. Copyright 2013/2019 [acesso em 13 ago 2019]. Vigilância em saúde. Disponível em: http://www.saude.gov.br/vigilancia-em-saude/vigilancia-ambiental/vigifis/radiacaonao-ionizante. 
11. Escola politécnica. Poli-USP quer ampliar pesquisas na área de energy harvesting. [publicação online]; 2019 [acesso em 13 ago 2019]. Notícias. Disponível em:

https://www.poli.usp.br/noticias/2186-poli-usp-quer-ampliar-pesquisas-na-area-de-energyharvesting.html.

12. Rodrigues, JF. Circuito RF para reaproveitamento de energia sem fio. (Projeto de pesquisa). Florianopólis: Universidade Federal de Santa Catarina; 2017.

13. Jorge LFR. Sistema de transmissão de energia eléctrica sem utilização de cabos nem meios ferromagnéticos. (Dissertação de Mestrado). Portugal: Faculdade de Ciências e Tecnologia Universidade de Nova Lisboa; 2012.

14. Makinde K, Enemuoh FO, Lawal OK, Umar I, Abubakar B, Mahmood MK. A review of wireless power transmission via solar power satellite. IOSR Journal of Engineering (IOSRJEN). Jun, 2014; Vol. 04, PP 09-12.

15. Tesla Tower: The Tragic Story of Nikola Tesla's Wardenclyffe Wireless Station. [publicação online] 2018. Disponível em: https://www.ststworld.com/the-tragic-story-of-nikolateslas-wardenclyffe-wireless-station/.

16. Jorge LFR. Sistema de transmissão de energia eléctrica sem utilização de cabos nem meios ferromagnéticos. (Dissertação de Mestrado). Portugal: Faculdade de Ciências e Tecnologia Universidade de Nova Lisboa; 2012.

17. Popular Science. Secreto of perpetual flinght? / Beam-Power Plane. Jan 1988; 62 - 63.

18. Brown WC. Rectenna Technology Program: Ultralight $2.45 \mathrm{Ghz}$ rectenna and $20 \mathrm{GHz}$ rectenna. NASA Contractor Report CR 179558, Contract NAS3-22764, NASA LeRC, Mar. 1987.

19. Brown WC, Mims JR, Heenan NI. An Experimental Microwave-Powered Helicopter, 965 EEE International Convention record, Vol. 13, Part 5, pp. 225-235.

20. Pereira SDD. Propagação e radiação de ondas eletromagnéticas em ambientes urbanos. (Dissertação de Mestrado). Portugal: Instituto Superior Técnico Lisboa; fev. 2014.

21. Joab Júnior SS. (2018) Hans Christian Oersted. [Publicação online]; 2018 [acesso em 29 abr 2018]. Educação. Disponível em: http://mundoeducacao.bol.uol.com.br/fisica/hanschristianoersted.htm.

22. Silva DCM. Experimento de Oersted. [Publicação online]; 2018 [Acesso em 29 de abril de 2018] Brasil Escola. Disponível em: https://brasilescola.uol.com.br/fisica/experimentooersted.htm. 
23. Cavalcante KG. Lei de Gauss. [Publicação online]; 2018 [Acesso em 29 de abril de 2018]. Mundo educação. Disponível em: http://mundoeducacao.bol.uol.com.br/fisica/leigauss.htm.

24. Nassif L. O legado do matemático Carl Gauss. [Publicação online]; 2012 [Acesso em 29 de abril de 2018]. Jornal GGN. Disponível em: https://jornalggn.com.br/blog/luisnassif/olegadodo-matematico-carl-gauss.

25. Fundamentos de física. Universidade Federal de Santa Maria. 29 de abr 2018. Disponível em: http://coral.ufsm.br/gef/l-eletro.html.

26. Lei de Gauss. Grupo escolar. 29 de abr 2018. Disponível em: https://www.grupoescolar.com/pesquisa/lei-de-gauss.html.

27. Halliday, David. David. Fundamentos de física, volume 3: Eletromagnetismo / David Halliday, Robert Resnick, Jearl Walker. 9.ed. Rio de Janeiro: Livro técnico e cientifico; 2012.

28. Silva DCM. Enunciando a Lei de Biot-Savart. [Publicação online]; 2018 [Acesso em 29 de abril de 2018]. Mundo educação. Disponível em: http://mundoeducacao.bol.uol.com.br/fisica/enunciando-lei-biotsavart.htm.

29. Forças Magnéticas, Campos Magnéticos E A Lei De Faraday. [Publicação online]; 2018 [Acesso em 29 de abril de 2018]. KHANACADEMY. Disponível em: https://pt.khanacademy.org/science/physics/magnetic-forces-and-magneticfields/magneticflux-faradays-law/a/what-is-faradays-law.

30. Equações de Maxwell na Forma Fasorial. [Publicação online]; [Acesso em 30 de abril de 2018] Universidade estadual paulista - UNESP. Disponível em: www.feis.unesp.br/Home/departamentos/engenhariaeletrica/optoeletronica/equacoesdemawell.pdf.

31. Dartora CA. Teoria do campo eletromagnético e onda. Disponível em: https://sites.google.com/site/eletromagnetismopy5aal/home/ondaseletromagneticaspy5aal/1OndasEletromagneticaspy5aal.pdf

32. Jones RV. Heinrich Hertz's Wireless Experiment (1887). Harvard SEAS. [30 de abr 2018].[Publicação Online]. Disponível em: http://people.seas.harvard.edu/ jones/cscie129/nu_lectures/lecture6/hertz/Hertz_exp.html

33. 1888: Hertz demonstra existência das ondas eletromagnéticas. [Publicação online]; 2014. [Acesso em 30 de abril de 2018] Terra notícias. Disponível em: https://www.terra.com.br/noticias/1888-hertz-demonstra-existencia-dasondaseletromagneticas, 1a15340d0a9f9410VgnCLD200000b1bf46d0RCRD.html 
34. Oliveira PP et al. Física em contextos: pessoal, social e histórico: eletricidade e magnetismo, ondas eletromagnéticas, radiação e matéria. 1 ed., v. 3. [Publicação online]; 2012. [Acesso em 30 de abril de 2018]. Disponível em:

http://clickgratis.blog.br/FisicaTubarao/479027/definicaosobre-ondas-eletromagmeticas.html

35. Halliday, David. Fundamentos de física, volume 4: Óptica e física moderna / David Halliday, Robert Resnick, Jearl Walker. 10.ed. Rio de Janeiro: Livro técnico e cientifico; 2016.

36. Dicionário Aurélio. Significado de Antena. [Publicação online]; 2018. [Acesso em 30 abr 2018]. Disponível em: https://dicionariodoaurelio.com/antena.

37. IEEE Standard for Definitions of Terms for Antennas. in IEEE Std 145-2013 (Revision of IEEE Std 145-1993), vol., no., pp.1-50, March 62014 doi: 10.1109/IEEESTD.2014.6758443 keywords: \{IEEE standards;antennas;IEEE Std 145-1993 Revision;IEEE Std 145- 2013;IEEE standard;antenna term definitions;Antennas;IEEE standards;Terminology;IEEE 145; antennas;definitions;terms \}, URL:

http://ieeexplore.ieee.org/stamp/stamp.jsp?tp=\&arnumber=6758443\&isnumber=67 58442 .

38. Stutzman, Warren L, Gary A. Teoria e projeto de antennas / Warren L. Stutzman, Gary A. volume 1. 3.ed. Rio de Janeiro: Livro técnico e cientifico; 2017.

39. Volpato JV. Gerador automático de diagrama de irradiação para antenas na faixa VHF. (Dissertação de mestrado). Taubaté - SP: Universidade de Taubaté; 2006.

40. Ribeiro, JAJ. Engenharia de antenas: fundamentos, projetos e aplicações. 1ed. São Paulo: érica, 2012.

41. Carvalho, LP. Introdução a sistemas de telecomunicações abordagem histórica. 1ed. Rio de Janeiro: LTC, 2014.

42. Rocha, JPM, Mendes, JC, Lima, JS, Silva, CJ, Neto AG.Caracterização e confecção de uma antena de microfita para recepção de TV digital e aplicação em notebooks através do Ansoft HFSS. Revista principia. Instituto Federal de Educação, Ciência e Tecnologia da Paraíba; dez 2012.

43. Ballanis, CA. Teoria de antenas: análise e síntese. tradução J. R. Souza ; revisão Silvio Ernesto Barbin, J. R. Souza. - [Reimpr.]. - Rio de Janeiro : LTC, 2014. 2v.

44. Oliveira, EEC. Desenvolvimento de antenas de microfita e antena DRAbroadbandlultra wideband para sistemas de comunicação sem fio utilizando pós cerâmicos nanoestruturados. (Tese de Doutorado). Universidade Federal do Rio Grande do Norte; 2011. 
45. NightWire enginnering. Copyright (C) 2019 NightWire Engineering [publicação online]. Disponível em: http://nightwireeng.blogspot.com/2013/11/projeto-final-antenas-epropagacao.html.

46. Araújo, NMS, Vieira, MS. Estudo e simulação de arranjo de antenas. Revista Mackenzie de Engenharia e Computação. Universidade Presbiteriana Mackenzie. São Paulo; 2016. v. 16, n. 1, p. 34-53.

47. Caetano, LM. Aplicações de arranjos de antenas de microfita com patch supercondutor. (Dissertação de Mestrado). Rio Grande do Norte: Universidade Federal do Rio Grande do Norte; 2010.

48. Gure, AE. Design rectenna for wireless energy harvesting. (Dissertação de Mestrado). Tun Hussein Onn Malaysia: Faculty of Electrical and Electronic Engineering Universiti; 2015.

49. Zanon, FOS. Sistema para reaproveitamento de energia eletromagnética utilizando rectenna aplicado ao monitoramento de temperatura. Belo Horizonte: Centro federal de educação tecnológica de minas Gerais; 2017.

50. Shuai, JI, Hua QI , Huifeng Z. Rectenna Serves 2.45-GHz Wireless Power Transmission. Rev Microwaves e RF. 26th International Trade Fair for Electronic Components, Systems and ApplicationsMesse München; 11-14 nov 2014.

51. Oliveira, Maciel \& Batista, Fabricio \& Carneiro de Oliveira, Elder \& Henrique, Paulo \& Fonseca, Da \& Silva Junior, Paulo \& Júnior, Silva \& Carlos, Raimundo \& Freire, Silvério \& Jean, Alexandre \& Serres, René. (2016). Técnicas de Casamento de Impedâncias por Linha de Microfita em Antenas Patch Circular para Tecnologia ISM em 2,4 GHz.

52. Telebrasil. (2019) Associação brasileira de telecomunicações. [Publicação online]; [acesso 07 de março de 2019]. Disponível em: http://www.telecocare.com.br/telebrasil/erbs/ 